ISSN: 0213-2060

DOI: https://doi.org/10.14201/shhme2018362117146

\title{
LA FORMACIÓN DE LOS DIPLOMÁTICOS EN LA CASTILLA BAJOMEDIEVAL ${ }^{1}$
}

\section{The Training of Diplomats in Late Medieval Castile}

Óscar VILLARROEL GONZÁLEZ

Depto. de Historia de América y Medieval y Ciencias Historiográficas. Facultad de Geografia e Historia. Universidad Complutense. C/ Profesor Aranguren, s/n. Ciudad Universitaria. E-28040 MADRID. C. e.: ovillarroel@ghis. ucm.es

Recibido: 2018-01-30

Revisado: 2018-11-09

Aceptado: 2018-11-09

RESUMEN: Si la información sobre los embajadores castellanos es, en ocasiones, escasa, lo mismo ocurre en cuanto a la información de que disponemos sobre su formación. A lo largo del presente trabajo se analiza de una forma general lo que conocemos sobre los estudios que pudieron haber tenido esos enviados diplomáticos. Partiendo de la visión que en la misma época se tenía sobre la formación ideal, se realiza después un análisis cuantitativo sobre los datos de que disponemos hoy.

Palabras clave: Diplomacia; Castilla; Formación; Estudios; Servicio regio.

ABSTRACT: The sources are very poor in terms of the history of diplomacy in Castile. The same applies to the training of ambassadors, but in a more serious way. In this work, a general analysis is made, based on the ideal vision of the ambassador at that time, and then making a quantitative analysis with the data available today.

Keywords: Diplomacy; Castile; Training; Studies; Royal service.

1 El presente trabajo se encuentra enmarcado dentro del Proyecto HAR2016-76174-P «Expresiones de la cultura política peninsular en las relaciones de conflicto (Corona de Castilla, 1230-1504)», del programa estatal de Fomento de la Investigación Científica y Técnica de Excelencia, Ministerio de Economía y Competitividad. 
LA FORMACIÓN DE LOS DIPLOMÁTICOS EN LA CASTILLA BAJOMEDIEVAL ÓSCAR VILLARROEL GONZÁLEZ

118

SUMARIO: 0 Introducción. 1 Un primer problema: las fuentes para la diplomacia castellana. 2 La formación en las fuentes. 2.1 Las menciones en la documentación universitaria. 2.2 Las menciones en la información de índole general y diplomática. 3 La formación de los embajadores. 3.1 El embajador ideal en la baja Edad Media castellana. 3.2 La nómina de los embajadores. 3.3 La formación de los que conocemos. 4 Conclusiones. 5 Anexo: embajadores y estudios. 6 Referencias bibliográficas.

\section{INTRODUCCIÓN}

La formación fue teniendo, según avanzaron los siglos de la plena y, sobre todo, baja Edad Media, cada vez una mayor importancia. El tener unos estudios específicos en algunas cuestiones se hizo necesario para un ejercicio de determinadas profesiones y oficios, especialmente para el servicio administrativo a las distintas instancias de poder. Esto iba mucho más allá, obviamente, de los conocimientos básicos (leer, escribir), siendo, de forma paulatina, cada vez más importante el haber cursado estudios universitarios. Esto, evidentemente, afectó de la misma forma a todos aquellos que pasaban a servir al poder regio en cualquiera de sus diversos ámbitos, cada vez más diversificados a lo largo del periodo bajomedieval.

La construcción de los aparatos monárquicos y de los poderes soberanos conllevó la necesidad, cada vez mayor, de contar con gente formada que pudiese acometer una serie muy variada de tareas necesarias para la administración y el ejercicio del poder público. Se ha analizado ya desde hace mucho tiempo cómo los letrados fueron estando cada vez más presentes en el entorno de las monarquías, especialmente entre sus servidores y en aquellos oficios para los cuales una formación avanzada era necesaria ${ }^{2}$. Esto también fue evolucionando, y cada vez fue más importante el hecho de tener una formación universitaria determinada, y los «letrados» pasaron a ser sustituidos por universitarios: bachilleres, licenciados, doctores y «maestros» ${ }^{3}$. De esta forma, la formación en derecho (fundamentalmente) fue teniendo cada vez mayor peso entre los servidores regios en los diversos ámbitos en los que el poder regio fue desarrollándose a lo largo del periodo bajomedieval, como se ha mostrado ya en alguna ocasión ${ }^{4}$.

La diplomacia, evidentemente, no suponía una excepción al respecto. Es sabido hoy día que el ejercicio de la diplomacia, proveniente de la antigüedad como modo de ejercer la negociación política entre dos poderes, fue evolucionando a lo largo del periodo medieval. Los siglos pleno y bajomedievales supusieron un momento de afianzamiento

2 Moxó y Ortiz de Villajos, Salvador de. «La promoción política y social de los 'letrados' en la corte de Alfonso XI». Hispania, 1975, vol. 15, pp. 5-29; y del mismo autor: «La elevación de los 'letrados' en la sociedad estamental del siglo XIV». En XII Semana de Estudios Medievales. Pamplona: Institución Príncipe de Viana, 1974, pp. 181-215.

3 Este no es un grado en sí mismo: suele atribuirse a doctores, especialmente en Teología, que tenían una especial relevancia.

4 Véase, por ejemplo, Villarroel González, Óscar. «Los poderes imbricados: papado y monarquía». En Pena González, Miguel Anxo y Rodríguez-San Pedro Bezares, Luis Enrique (coords.). La universidad de Salamanca y el Pontificado en la Edad Media. Salamanca: Publicaciones Universidad Pontificia de Salamanca, 2014, pp. 89-107, en concreto pp. 95-98. 
de unas formas determinadas, que estuvieron en la base de la diplomacia moderna. Para el ejercicio de esas funciones, lógicamente, cada vez fue necesaria también una formación. La cuestión que podemos plantearnos hoy es ¿qué formación era idónea para un embajador en el periodo medieval? ¿Hay algún perfil concreto que destaque entre los embajadores? ¿Era la universidad un requisito imprescindible para el embajador? Y sin duda las respuestas son complicadas, o, al menos las que podamos dar, no son fáciles ni, sobre todo, definitivas. A lo largo de las siguientes páginas intentaremos contestar de forma, al menos, aproximada, pero iremos repasando al menos los principales problemas que nos plantean las cuestiones, así como los aspectos a tener en cuenta.

\section{UN PRIMER PROBLEMA: LAS FUENTES PARA LA DIPLOMACIA CASTELLANA}

Es de sobra conocida la cuestión de la escasez de las fuentes en lo que atañen a la monarquía bajomedieval castellana ${ }^{5}$. La falta de un archivo organizado y estable en el periodo bajomedieval hace que todo lo tocante a la organización interna de los aparatos administrativos regios lo conozcamos, en muchos casos, solo superficialmente o por fuentes parciales en cuanto a su contenido (que no en cuanto a su objetivo) ${ }^{6}$. Es conocido, además, el hecho de que no se conserven los registros de la cancillería anteriores a los Reyes Católicos, aunque sepamos que existieron ${ }^{7}$. La no conservación de los registros, por ejemplo, así como de la correspondencia de los reyes (como sí ocurre en la Corona de Aragón), supone un problema fundamental a la hora de poder acceder al conocimiento sobre cómo funcionaba esa diplomacia, dado que nos faltan los nombramientos, poderes, instrucciones... en la mayor parte de las embajadas que se desarrollaron en el periodo bajomedieval.

Solo en casos contados se han conservado conjuntos un tanto excepcionales de documentación de índole diplomática, que sin duda es solo una pequeña parte de lo que podemos sospechar que existió. Así, por ejemplo, es el caso de algunos conjuntos conservados en la sección de Estado de Simancas, donde en el momento de organizarse el archivo, se concentró, por orígenes o destino, lo que restaba en los archivos regios de parte de esas comunicaciones (junto con documentación posterior y de otras instancias). La conservación en esa sección simanquina de algún tratado, algunas cartas de embajadores, algún nombramiento e incluso algunas instrucciones de la primera mitad del siglo xv podríamos considerarla casi como accidental, y solo

5 Villarroel González, Óscar. «Corte y diplomacia en la Castilla bajomedieval». Mélanges de la Casa de Velázquez. Nouvelle série, 2015, vol. 45, n.o 2, pp. 105-124. Disponible en línea desde el 15 de noviembre de 2017, URL: http://mcv.revues.org/6537

6 EL Archivo General de Simancas se organizó y fundó en tiempos de Carlos I y Felipe II: RodríguEz DE Diego, José Luis. «La formación del Archivo de Simancas en el siglo Xvi. Función y orden internos». En López Vidriero, M. ${ }^{a}$ Luisa y Cátedra, Pedro M. (dirs.). Coleccionismo y bibliotecas (siglos XV-XViII). Salamanca: Universidad de Salamanca-Patrimonio Nacional, 1998, pp. 519-557.

7 No solo se mencionan en las Partidas, sino que es habitual encontrar documentos originales regios con la indicación «Registrado». Montojo Montojo, Vicente. «Los fondos archivísticos como fuentes para el estudio de las cancillerías reales en las edades Media y Moderna». Miscelánea Medieval Murciana, 1999-2000, vol. XXIII-XXIV, pp. 75-97, en concreto 84 y ss. 
se incrementa con la llegada de los Reyes Católicos (fruto, sin duda, de la primera labor creadora del archivo).

Hoy día podemos sospechar que hubo conjuntos más amplios de documentación, fruto, en ocasiones, de las propias misiones diplomáticas ${ }^{8}$. Estas concentraban toda la documentación generada y de interés para la legación y se enviaba a la Corte regia, como se puede comprobar con el legajo K1711. En este legajo se concentró toda la documentación de la legación castellana en Basilea (relativa al Concilio y las cuestiones de peso en Castilla, sobre la política reformista, las peticiones regias al Concilio, la diplomacia con reinos aliados y sobre sus problemas con otros reinos -especialmente el enfrentamiento franco-inglés-, las misiones anexas a la conciliar: embajadas ante el emperador, documentación de acuerdos diplomáticos donde están presentes, aunque sean ajenos a Castilla...). Gracias a él, además, conocemos la comunicación existente entre los embajadores y el monarca (por ejemplo, que se le enviaba documentación y cartas de vez en cuando, aunque se reflejasen en el volumen), lo que incluía todo tipo de documentación que, siendo ajena a la legación castellana, se consideraba importante para su misión en Basilea. Gracias a ello, se conserva uno de los fondos excepcionales de la diplomacia bajomedieval castellana.

Sin embargo, por desgracia para los historiadores, eso no es la norma sino la excepción. Eso ha hecho que las fuentes disponibles a la hora de analizar y estudiar ese ámbito de la creciente autoridad regia castellana sean reducidas. Y por ello se ha tenido que recurrir en muchas ocasiones a todo tipo de fuentes en las que poder localizar información sobre misiones diplomáticas, embajadores, acuerdos... Es decir, nuestras fuentes de información son parciales (por incompletas, aunque algunas, como las crónicas, sean además subjetivas ${ }^{9}$ ) y en muchas ocasiones son ajenas a la propia diplomacia. Esto tiene como consecuencia que hay muchos aspectos de su funcionamiento que, por ahora, podemos sospechar, pero no confirmar. Esto afecta, por ejemplo, al hecho de que no podamos, de momento, presentar una nómina completa de misiones diplomáticas castellanas, puesto que la consulta de nuevas fuentes sigue aportando, año tras año, nuevas misiones que hasta ahora habían pasado desapercibidas. Y eso incluye, obviamente, la información de los embajadores, que no podemos dar por cerrada aún.

\section{LA FORMACIÓN EN LAS FUENTES}

Si el conocimiento exhaustivo de la diplomacia y las embajadas castellanas es aún incompleto, lo mismo ocurre, y por razones semejantes en ocasiones, con la información que tenemos de los propios actores de la diplomacia: los embajadores, mensajeros, enviados... En este sentido hay una diferencia importante según pasa el tiempo. Si antes del

8 La hipótesis fue presentada en: Villarroel González, Óscar. «Diplomacia y construcción monárquica: la participación eclesiástica castellana». En VILAR, Hermínia y BranCo, Maria João. The Medieval Monarchy and its legitimating strategies: the role of ecclesiastics, scholars and jurists (12 $12^{\text {th }} 15^{\text {th }}$ centuries), (en prensa).

9 Para un análisis de las crónicas bajomedievales castellanas en su conjunto: Gómez Redondo, Fernando. Historia de la prosa medieval castellana. Madrid: Cátedra, 1998-2007, 4 vols. 
siglo XV es poco habitual que las fuentes mencionen los estudios del personaje en cuestión, esto cambia con la llegada del último siglo bajomedieval. Para llegar a conocer los estudios de un personaje concreto, embajador en nuestro caso, tenemos dos vías posibles: que se mencione en la documentación su grado de estudios, o que se le mencione en la documentación universitaria y que rodea a la Universidad.

\subsection{Las menciones en la documentación universitaria}

En este segundo punto es donde, en la mayor parte de las ocasiones, podemos tener más posibilidades de encontrar información. Conocemos bastante bien el curso de los estudios que podían seguir aquellos que querían (y podían) formarse ${ }^{10}$. También el punto más elevado de todos ellos: la Universidad, pese a las variaciones que podía haber entre unas y otras ${ }^{11}$. El curso de los estudios de un aspirante a servidor regio también es conocido y ha sido tratado en alguna ocasión ${ }^{12}$. Es por ello que en la documentación que tiene relación con las universidades es donde podemos encontrar noticias sobre la formación de los, posteriormente, embajadores.

A este respecto son muchas las lagunas que tenemos aún y muchas de ellas son difícilmente subsanables. No contamos con listas de matriculados en la Universidad hasta bien avanzado el siglo xvi, lo que dificulta bastante la labor. En Salamanca, por ejemplo, el primer libro de matrícula conservado es de $1546^{13}$. Sin embargo, por otras vías podemos en ocasiones encontrarnos con información de alumnos en diversas universidades. Así, por ejemplo, las obras de Beltrán de Heredia sobre la Universidad de Salamanca nos ofrecen abundantes datos de personajes que allí estudiaron ${ }^{14}$. En ellas se recogen noticias tanto de archivos salmantinos como romanos sobre profesores y estudiantes de esa universidad, lo que nos permite en ocasiones localizar a posteriores servidores regios ${ }^{15}$.

Esto, sin embargo, no es generalizable a otros estudios peninsulares. De los centros universitarios del periodo no tenemos estudios semejantes que nos permitan conocer a los escolares que pasaron por sus aulas. Buen ejemplo de nuestro escaso conocimiento al respecto es que del segundo gran centro castellano, Valladolid, apenas tenemos dos obras

10 Puede verse un somero acercamiento en Redondo García, Emilio y otros. «La educación durante la Edad Media». En Redondo García, Emilio (coord.). Introducción a la historia de la educación. Barcelona: Ariel, 2001, pp. 251-380.

11 Barcala Muñoz, Andrés. "Las universidades españolas durante la Edad Media». Anuario de Estudios Medievales, 1985, vol. 15, pp. 83-126.

12 Villarroel GonzÁlez, Óscar. «Formación para el servicio del rey y la Iglesia en la Castilla bajomedieval». En Sabaté, Flocel (ed.). La formació de la personalitat a l'Edat Mitjana. Lleida: Pagès editors, 2016, pp. 149-167.

${ }_{13}$ Archivo de la Universidad de Salamanca, (en adelante AUSA), 270.

14 Tanto Beltrán de Heredia, Vicente. Cartulario de la Universidad de Salamanca. Salamanca: Ediciones Universidad de Salamanca, 1970, vol. 1; como Beltrán de Heredia, Vicente. Bulario de la Universidad de Salamanca. 3 vols. Salamanca: Ediciones Universidad de Salamanca, 1966-1967.

15 Algunos ejemplos en: Villarroel González, «Formación», pp. 155 y ss., o «Los poderes imbricados», pp. 97 y ss. 
LA FORMACIÓN DE LOS DIPLOMÁTICOS EN LA CASTILLA BAJOMEDIEVAL ÓSCAR VILLARROEL GONZÁLEZ

\section{2}

que tratan de su historia ${ }^{16}$. Menos información hay, incluso, sobre centros posteriores como los estudios murcianos, o el estudio general de Alcalá de Henares.

En los centros extranjeros nos ocurre lo mismo. Solo en el caso de Bolonia tenemos un estudio sobre los hispanos en aquella Universidad, el estudio de García y García, que atendió el periodo de principios del siglo $\mathrm{XIV}^{17}$, y también tenemos información de finales del XIV y el XV ${ }^{18}$, así como de principios del XVI ${ }^{19}$. Pero esto no es generalizable, pues nada sabemos de los castellanos que se formaron en París o en otros centros franceses. El conocerlo, como veremos, es en muchas ocasiones cuestión de puro azar.

\subsection{Las menciones en la información de indole general y diplomática}

En otras ocasiones, como se ha dicho, es posible encontrar en muy diversas fuentes que se utilizan para la historia diplomática información sobre la formación de aquellos que compusieron las embajadas castellanas en el periodo. Dentro de las fuentes podríamos dividir por un lado las documentales y por otro las narrativas.

Entre las narrativas, principalmente las crónicas, nos encontramos con una doble dificultad. Para empezar, pocas misiones son recogidas por los cronistas y en la mayor parte de ellas ni siquiera se reflejan todos los componentes de la embajada, algo que se ha podido apreciar hace ya años ${ }^{20}$. Ejemplo de ello lo encontramos en la misión castellana que estuvo negociando en Ágreda desde 1431 con navarros y aragoneses. La crónica ni siquiera nos informa de quiénes fueron los procuradores castellanos ${ }^{21}$, y es documentación específica la que nos informa de los siete delegados castellanos: Juan Martínez Contreras, Juan Hurtado de Mendoza (señor de Almazán), el doctor Fernando González Dávila (refrendario, oidor y del Consejo), el doctor Pero González del Castillo (oidor y del Consejo), Juan Fernández de Toro (oidor), el deán y capellán regio Pedro de Bocanegra y el maestro en Teología fray Martín de Vargas ${ }^{22}$.

Además, las crónicas tampoco suelen informar de los estudios de los personajes que citan (algo que ocurre en pocas ocasiones), de modo que tenemos que encontrar esa in-

16 Velázquez de Figueroa, Vicente y otros. Historia de la Universidad de Valladolid. Valladolid: Imprenta Castellana, 1918; y la más reciente Riвот García, Luis Antonio (coord.). Historia de la Universidad de Valladolid. Valladolid: Universidad de Valladolid, 1989.

17 García y García, Antonio. «Escolares ibéricos en Bolonia. 1300-1330». En Estudios sobre los origenes de las universidades españolas. Homenaje de la Universidad de Valladolid a la Universidad de Bolonia en su IX centenario. Valladolid: Universidad de Valladolid, 1988, pp. 113-134.

18 Pérez Martín, Antonio. «Españoles doctorados en Bolonia en derecho civil o canónico (13691788)». En Rodríguez-San Pedro Bezares, Luis Enrique (dir.). Las universidades hispánicas de la monarquia de los Austrias al Centralismo liberal. Salamanca: Universidad de Salamanca, 2000, pp. 373-386.

19 Constance Mathers, Jones. "Students from Burgos at the Spanish College in Bologna (15001560)». The Sixteenth Century Journal. The Journal of Early Modern Studies, 1987, vol. 18, pp. 545-556.

20 Beceiro Pita, Isabel. «La importancia de la cultura en las relaciones peninsulares (siglo Xv)». Anuario de Estudios Medievales, 1999, vol. 29, pp. 79-104, en concreto pp. 86-87.

21 Galíndez de Carvajal, Lorenzo (comp.). Crónica del serenísimo príncipe don Juan II. En Crónicas de los Reyes de Castilla, Madrid: Rivadeneyra, 1876, vol. 2, p. 487.

22 Archivo de la Corona de Aragón (en adelante ACA), Cancillería, Registros, 2937, fols. 41v-45r. 
formación en otros ámbitos. Un buen ejemplo lo encontramos en Pedro de Bocanegra: este fue enviado al rey de Navarra en 1429 , según informa la crónica de Juan $\mathrm{II}^{23}$, pero no se mencionan sus estudios, dato que solo nos ofrece documentación vaticana que nada tiene que ver con la misión ${ }^{24}$. De esta forma, es necesario un rastreo documental muy amplio, así como un cierto trabajo biográfico sobre cada uno de los embajadores, para conseguir complementar la información que tenemos.

Más aún, se nos añade otro problema. No es habitual que antes de mediados del siglo XIV la documentación nos informe de los estudios o formación de los personajes en cuestión. Solo a partir de ese momento el dato nos es ofrecido y, hay que añadir, ni siquiera siempre. Si atendemos a los embajadores castellanos que aparecen documentados entre la documentación conservada en los Archives Nationales, por ejemplo, no aparecen apenas menciones a estudios a lo largo de los siglos XIII y XIV salvo contadas excepciones. No deja de ser curioso que, incluso en el XIII, a veces sí se menciona la condición de «magister» de algunos emisarios franceses ${ }^{25}$, pero hay menos ejemplos de los castellanos, no existiendo ninguno hasta 1294 . En concreto, se trata del maestro Nicolás, de quien se dice que es medicum et consiliarium del rey ${ }^{26}$.

El inicio del siglo XIV no supuso grandes cambios, existiendo pocas menciones entre los castellanos. De hecho ningún cambio, dado que es el mismo embajador el único del que tenemos conocimiento de su formación: de nuevo el magister Nicolás, que seguía siendo médico y consejero del rey, en esos momentos ya de Fernando IV ${ }^{27}$. Esta tónica iría cambiando con el tiempo, y es a lo largo del siglo xIV cuando empezamos a tener cada vez más información en la documentación sobre la formación de los embajadores y enviados. De hecho, si atendemos a la frecuencia de los datos, realmente es desde 1378 cuando empezamos a encontrar ese incremento real de forma más o menos frecuente, pues hasta entonces solo encontramos cuatro casos.

¿A qué se debe esa falta de información sobre los estudios y formación de los embajadores (algo que es común al conjunto de personajes)? ¿Falta de esa formación? ¿Falta de hábito en reflejarlo en la documentación? Es difícil saberlo. No podemos afirmar que solo se mencionase cuando sí tenían estudios, porque en ocasiones, ya hemos visto, los tenían y no siempre se mencionaba. Sea cual sea la razón, como se ha dicho, no es hasta el tercer cuarto del siglo XIV que empezamos a encontrar una cierta asiduidad en la mención de los estudios de los embajadores. Como se verá a continuación todo esto hace que los datos que aportamos sean poco menos que provisionales, y sin

23 Galíndez de Carvajal, Crónica, p. 452.

24 Archivio Segreto Vaticano (en adelante ASV), Registra Vaticana (en adelante RV), 329, fol. 15r-v.

25 Por ejemplo, de Guillaume de Castro Eraudi, clérigo del rey de Francia y canónigo de Reims, se dice que es «magister» en 1269, pero no indica la especialidad, además de lo laxo que supone ese grado: Archives Nationales, Paris (en adelante AN), J599, n. ${ }^{8}$. También a Pierre de Mornay, arcediano de Sologne, se le dice «magister», AN, J601, n. ${ }^{2} 22$. Así aparecen también Johannes Ducis, y Petrus La Rene, que son mencionados también como «magister»: AN, J. 601, n. ${ }^{\circ} 21$.

$26 \mathrm{AN}, \mathrm{J601}, \mathrm{n} .^{\circ}$ 26. En ese mismo documento, algo muy poco habitual, se nos habla también de Pascasio Martínez «iudicem nostrum», con lo que hemos de suponerle estudios en derecho. No deja de ser curioso que en esa misma negociación todos los negociadores franceses fuesen «magistri» (AN, J915, n. ${ }^{\circ} 1$ ).

27 AN, J601, n. ${ }^{\circ} 40$ bis. 
LA FORMACIÓN DE LOS DIPLOMÁTICOS EN LA CASTILLA BAJOMEDIEVAL

ÓSCAR VILLARROEL GONZÁLEZ

\section{4}

duda en el futuro, según profundicemos en el conocimiento de la historia diplomática castellana, irán variando.

\section{LA FORMACIÓN DE LOS EMBAJADORES}

Es interesante, sin duda, abordar la cuestión de cuál era la formación que tenían o debían tener aquellos que desarrollaron misiones diplomáticas en el periodo bajomedieval en Castilla. Esto se puede hacer desde dos puntos de vista, desde el punto de vista del propio periodo medieval (¿existía una conciencia de cuál era la mejor formación para un embajador?); y desde el punto de vista actual y del interés historiográfico (¿cuál era la formación real de los embajadores?).

Del primer aspecto sí tenemos ciertas nociones, dado que algunos autores ya en el periodo medieval hablaron o debatieron sobre esta cuestión. El segundo nos obliga a un análisis más cuantitativo que cualitativo y en el que hay que tener en cuenta los datos disponibles a día de hoy (número de embajadores), así como los datos que poseemos de cada uno de ellos (la formación que sabemos que tenían).

\subsection{El embajador ideal en la baja Edad Media castellana}

La regulación sobre los embajadores y los enviados diplomáticos a lo largo del periodo medieval no fue especialmente relevante. De hecho, es sabido cómo fueron diversas las palabras utilizadas a lo largo del periodo para referirse a aquellos que realizaban este tipo de tareas desde el ya clásico trabajo de Queller ${ }^{28}$, hasta otros más recientes con un marco cronológico más amplio ${ }^{29}$. Así, gracias a ellos (y otros muchos trabajos de base ${ }^{30}$ ) conocemos la evolución de los términos, desde los legati y nuntii bajoimperiales, hasta la inclusión también del término missus ya en época tardoantigua. Es en los siglos pleno y bajomedivales cuando los términos antiguos van siendo sustituidos por otros: procuratores (proctor en inglés, procurador en castellano), ambaxiator (ambasciatore en italiano, ambasseor en francés, embaxador en castellano)... Este último, nace en Italia en torno al siglo XII y se expandirá por el resto del Occidente a lo largo del periodo bajomedieval ${ }^{31}$. Todo esto, sin embargo, iba unido a un uso ambiguo de los términos, pues normalmente no se utiliza uno solo y es habitual que se produzca la

28 Queller, Donald E. The Office of Ambassador in the Middle Ages. Princeton: Princeton University Press, 1967.

29 Moeglin, Jean-Marie (dir.) y Péquignot, Stéphane. Diplomatie et "relations internationales» au Moyen Âge (IXe-XVe siècle). Paris: Presses Universitaires de France, 2017. Interesan para este aspecto, especialmente, pp. 348-359.

${ }_{30}$ Véase al respecto la bibliografía aportada en el magnífico trabajo de Moeglin y Péquignot indicado en la nota anterior.

31 Ochoa Brun, Miguel Ángel. Historia de la diplomacia española. Madrid: Ministerio de Asuntos Exteriores, 2003, vol. 3, p. 309; Moeglin (dir.) y PÉquignot, Diplomatie, p. 356. 
utilización de varios a la vez ${ }^{32}$. Sin embargo, existen diferencias según el poder del que emanan esos enviados, y según la importancia y los poderes concedidos ${ }^{33}$.

Son siglos, además, en los que en algunos casos empieza a producirse legislación sobre el cargo de embajador, y cómo debe ser elegido y desarrollar su labor, con Venecia, sin duda, al frente de esa labor ya en el siglo XIII $^{34}$. En Castilla no se fue mucho a la zaga. A mediados del siglo XIII se traducía, por orden del rey Fernando III y para su hijo Alfonso, la obra Poridat de poridades, en la que se refeja ya la figura del embajador o enviado ${ }^{35}$. Esta obra se ha dicho que es jalón fundamental para el contexto político y cortesano del siglo XIII castellano ${ }^{36}$. No en vano su primer traductor ya la consideraba un regimiento de príncipes $^{37}$. Sea como fuere, se difundió en Castilla ya en el $\mathrm{XII}^{38}$, lo que motivó sin duda el interés en ella de Fernando III para la formación de su hijo. En esta obra se dedica un capítulo a los enviados de los soberanos, el quinto, lo que ha hecho que se le preste especial atención ${ }^{39}$. En él se habla del «mandadero» diciendo:

El omme demuestra el sesso del que lo enbía que es su ojo en lo que non vee et es su oreja en lo que non oye et es su lengua o non açierta, pues convien vos que el vuestro mandadero que lo escojades el mellor que ovieredes en vuestra corte, et de seso et de entendimiento et parescer et fialdad et de escusar las cosas en que puede caer en culpa ${ }^{40}$.

Además, hay que tener en cuenta que esta obra tuvo cierta influencia (sus redactores la utilizaron) en la elaboración de las Siete Partidas, obra de Alfonso X donde de nuevo nos encontramos esa atención a los embajadores, en concreto en la Segunda Partida, centrada en definir la autoridad real $^{41}$. Es la ley 21 del título IX la que define quiénes han de ser los enviados regios. Más allá de las semejanzas con el Secreto, con la influencia de

32 Sirva el ejemplo que ya ponía Ochoa Brun en su obra citada (Historia, vol. 3, p. 310), en el que el enviado de Alfonso X para promover su candidatura imperial es llamado «missaticum, legatum, ambaxiatorem, nuntium et procuratorem». Citando: Ballesteros Beretta, Antonio. Alfonso X el Sabio. Barcelona: Salvat, 1963, p. 166. El documento se encuentra también en DAUMET, Georges. Mémoire sur les relations de la France et la Castille de 1255 à 1320. Paris: Fontemoing, 1913, pp. 147-149; AN, J600, n.o 18.

33 Moeglin (dir.) y Péquignot, Diplomatie, pp. 357-359.

34 Gilli, Patrick. "Ambassades et ambassadeurs dans la législation statutaire italienne (XIII ${ }^{\mathrm{e}}$-XIV ${ }^{\mathrm{e}}$ siècle)». En Andretta, Stefano; PÉquignot, Stéphane y Waquet, Jean Claude. De l'ambassadeur. Les écrits relatifs à l'ambassadeur et à l'art de négocier du Moyen Âge au debut du XIXe siècle. Roma: École Française de Rome, 2015, pp. 57-85.

35 Bizzarri, Hugo Óscar (ed.). Secreto de los secretos = Poridat de las poridades: versiones castellanas del pseudo-Aristóteles secretum secretorum. Valencia: Universidad de Valencia, 2010. También Poridat de Poridades, ed. Lloyd A. Kasten. Madrid: Silverio Aguirre, 1957.

36 Gómez Redondo, Historia de la prosa, vol. 1, pp. 273 y ss.

37 Bizzarri, Secreto de los secretos, p. 16.

38 Ibidem, p. 18.

39 PÉQuignot, Stéphane. «Les ambassadeurs dans les miroirs de princes en Occident au Moyen Âge». En Andretta, Péquignot y Waquet, De l'ambassadeur, pp. 33-55, en concreto pp. 37 y ss.

40 Bizarri, Secreto de los secretos, p. 234; en este caso en la versión del ms. de la Universidad de Salamanca.

41 Sobre la Segunda Partida, su organización y construcción, en Gómez Redondo, Historia de la prosa, pp. 536 y ss. Se ha hecho ver el peso que tiene en la conexión el que esta parte de la obra tenga un cierto carácter de espejo de príncipes (PÉQUIGNOT, «Les ambassadeurs», p. 40). 
Aristóteles presente ${ }^{42}$, interesa aquí la mención que se hace a las condiciones que han de tener tales mandaderos: "et muy sabidores et de buena palabra», porque, si no, no tendrían «sabidoría para conosçer nin entender (...) et si de buena palabra non fuesen non sabríen bien mostar aquello que les mandasen decir» ${ }^{43}$. De esta forma el tener cierta capacidad intelectual se considera básico para el buen ejercicio de sus labores. Y en este sentido se manifiestan otras obras posteriores, más cercanas a la monarquía unas (como el Libro de los castigos del rey don Sancho ${ }^{44}$ ).

Buen ejemplo de cómo esto había calado en la sociedad política de aquel periodo es el hecho de que en algunas obras, incluso literarias, se tuviese conciencia de que los enviados y representantes del poder debían estar dotados de conocimientos y cultura. En el ámbito peninsular así se muestra, tanto en la Corona de Aragón como en la castellana. En la primera ya Llul lo indicaba en su novela alegórica Llibre de les besties: «saviesa de senyor es significada en missatgers savis, bé parlants, bé aconsellants, bé acordants (...) e que sien bé vestits» ${ }^{45}$. En la segunda la historiografía ha mostrado el caso del Rimado de Palacio, donde el canciller Ayala deja claro que: «sus embaxadores envía bien ordenados, Caballeros buenos, doctores muy letrados» ${ }^{46}$.

De modo que, como vemos, según avanza el periodo medieval va tomando clara conciencia de cuáles deben ser los valores a tener en cuenta a la hora de elegir un embajador, empezando por la sabiduría y el conocimiento, básicos para el desarrollo de sus labores. No olvidemos las palabras del canciller «doctores muy letrados». ¿Tuvo esto reflejo en la realidad?

\subsection{La nómina de los embajadores}

Ya se ha indicado cómo hemos de tener en cuenta, a la hora de abordar la formación de los embajadores castellanos en la Baja Edad Media, qué conocimiento podemos llegar a tener de ellos. A este respecto, se ha indicado cómo a día de hoy no podemos dar por cerrada, ni mucho menos, la búsqueda de esos embajadores en las fuentes; así como la escasez de datos que sobre ellos encontramos. Así, el contar con una nómina determinada de embajadores es fundamental a la hora de abordar un análisis sobre sus estudios y composición. Ya en ocasiones anteriores se han realizado análisis parciales, bien por destino ${ }^{47}$, o por tipo de embajador o misión ${ }^{48}$. En este caso se ha ampliado el marco a toda la Baja

42 PÉCQUignot, «Les ambassadeurs», pp. 41-42.

43 Las Siete Partidas, ed. Real Academia de la Historia. Madrid: Imprenta Real, 1807; vol. II, p. 76.

44 PÉQUignot, «Les ambassadeurs», pp. 45-46.

45 Citado por Ochoa Brun, Historia de la diplomacia, p. 328. Traducción castellana en: Llull, Ramón. Libro de las bestias, ed. Laureano Robles Carcedo. Madrid: Tecnos, 2006, p. 37.

46 Ya lo mostró OchoA Brun, Historia de la diplomacia, p. 328; más recientemente: PÉQUignot, «Les ambassadeurs», p. 47.

47 Beceiro Pita, «La importancia de la cultura».

48 Así, por ejemplo, Villarroel GonzÁlez, Óscar. «Eclesiásticos en la diplomacia castellana en el siglo XV». Anuario de Estudios Medievales, 2010, vol. 40, n.o 2, pp. 791-819; o la participación de eclesiásticos en la negociación de la paz entre los siglos XiII y xv: Villarroel GonZÁLEZ, Óscar. «Eclesiásticos en la negociación 
Edad Media, iniciando esta con el reinado de Alfonso X, y hasta la muerte de Enrique IV de Castilla (dado que la entrada del reinado de los Reyes Católicos en el análisis podría causar un serio desequilibro por las fuentes conservadas). Para realizar ese análisis (aún no definitivo) se han analizado un total de 340 embajadores documentados entre 1255 y $1470^{49}$. Son embajadores en misión, habiendo algunos de ellos que repitieron en más de una ocasión, pero que para el objeto del presente estudio es indistinto. Además, en el caso de aquellos con más de una titulación se tomado como referencia solo la de mayor importancia en cuanto al nivel de estudios.

Hay, evidentemente, amplias diferencias según avanzan los siglos. Estas, como veremos, afectan a los estudios que conocemos, pero además influyen también en el número de misiones que tenemos documentadas al menos hasta mediados del siglo xIV. Hay que tener en cuenta la falta de documentación que ya se ha comentado, y que es muy posible que altere la realidad de la nómina. Insisto por ello en el carácter un tanto provisional.

En total, como se ha dicho, se ha encontrado mención de 344 embajadores, de los cuales solo tenemos alguna información sobre su formación de un total de 111. Es decir, hay 233 no documentados frente a 111 sí documentados. La cifra es realmente increíble, apenas tenemos datos de un 32\% de los enviados castellanos.

\section{Conocimiento de la formación de los embajadores}

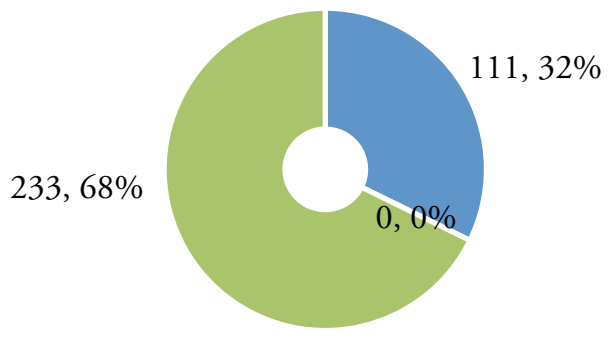

$$
\text { - Total con datos - Sin datos }
$$

Este dato, ciertamente indicativo de la pobreza de las fuentes en ocasiones, se ve matizado, en parte, si atendemos a diferentes periodos de tiempo. Para el análisis se ha dividido el tiempo analizado en cuatro periodos por razones que a continuación se detallarán: 1255-1369, 1370-1406, 1406-1454, 1454-1474. Dado que es en la segunda parte del siglo XIV cuando se ha notado un cambio importante en la cantidad de información que tenemos de los embajadores (en lo que toca a su formación, y en concreto en 1378), se ha decidido poner la cesura en el cambio de dinastía. El segundo periodo se ha extendido hasta la muerte de Enrique III, por el hecho de que el reinado de Juan II ha sido analizado de forma específica (aunque sea solo en lo que toca a los

de la paz en la Castilla bajomedieval». En Arranz Guzmán, Ana; Rábade Obradó, María del Pilar y VillaRroel González, Óscar. Guerra y paz en la Edad Media. Madrid: Sílex Ediciones, 2013, pp. 309-341.

49 También se han tenido en cuenta negociadores en territorio propio, pero con embajadores extranjeros. 
eclesiásticos), y eso podría suponer una distorsión. El tercero coincide con el reinado de Juan II precisamente por la razón aludida. Y, por último, el tiempo restante hasta el fin del periodo, que coincide con el reinado de Enrique IV.

Pues bien, en esos distintos periodos las cifras varían. Así, en el primero de ellos, de 1255 a 1369 , tenemos documentados de momento 74 embajadores, de los cuales sabemos algo sobre la formación de solo nueve de ellos (poco más del 12\%). La cifra es realmente baja, tanto en cuanto a los embajadores totales como en cuanto a aquellos de los que tenemos información. La primera cifra es plausible que se incremente, pero la segunda parece, dado el tipo de fuentes, extraño. No deja de ser curioso, además, el tipo de datos que tenemos de esos primeros embajadores. Solo de uno de ellos sabemos su nivel de estudios: Álvaro Sánchez de Cuéllar, bachiller en decretos y embajador en Inglaterra en 1362 para negociar un acuerdo con aquel reino ${ }^{50}$. Del resto, cuatro son juristas (con lo que les suponemos formación jurídica: Pascasio Martínez, juez de la corte de Sancho IV ${ }^{51}$; Alvar García de Ibles, juez de la casa del rey Alfonso $\mathrm{XI}^{52}$; Gómez Fernández de Soria, citado como jurista en la corte de Alfonso XI ${ }^{53}$; y García Gutiérrez Tello, juez en la Sevilla de Pedro $I^{54}$ ), dos sabemos que estudiaron en París (aunque es la misma persona, pero actuó en dos misiones distintas: el infante Sancho, arzobispo electo de Toledo ${ }^{55}$ ) y uno era maestro y médico (no se indica que la maestría sea en medicina: Nicolás, consejero de Sancho IV ${ }^{56}$ ). Como vemos, es un bagaje realmente corto el que tenemos como para lanzar grandes análisis. Sin duda en este periodo queda mucho por hacer todavía.

En el segundo, entre el advenimiento de la dinastía Trastámara y la muerte de Enrique III, nos encontramos con un periodo de intensa actividad diplomática. Las propias necesidades de afianzamiento en el trono de la nueva dinastía, sin duda, llevaron a ello en un primer momento, lo que explicaría la extensa actividad de Enrique ${ } I^{57}$ y que tengamos tantos datos de estos años. En esto, obviamente también tiene que ver el hecho de que conservemos poca documentación de los años anteriores, especialmente de Pedro I, sin duda por la propia intención de ignorar, lo que llevó al olvido, el reinado de este monarca. De cualquier forma, sin duda desde Enrique II la documentación empieza a crecer exponencialmente según nos acercamos al final del periodo medieval, y eso se refleja también en los datos que tenemos sobre la diplomacia.

50 Rymer, Thomas. Foedera, conventiones, literae et cuiuscunque generis inter reges Angliae et alios quosvis... III-2. Hagae Comitis: Apud Joannem Neaulme, 1740, pp. 60-61 y 91.

51 Daumet, Mémoire, p. 120; AN, J601, n. ${ }^{\circ} 26$, lo publica en anexo 23.

52 Serrano y Pineda, Luciano. "Alfonso XI y el papa Clemente VI durante el cerco de Algeciras". Cuadernos de Trabajo de la Escuela Española de Arqueología e Historia en Roma, 1915, pp. 1-33, en concreto p. 5, nota 5; ASV, Reg. Sup. 1-1, fol. 108.

53 Moxó y Ortiz de Villajos, Salvador de. «La sociedad política castellana en la época de Alfonso XI». Hispania, 1975, vol. 35, n. ${ }^{\circ}$ extra 6, pp. 187-326, en concreto p. 285.

54 López de Ayala, Pedro. Crónica del rey don Pedro primero, ed. Cayetano Rosell en Crónicas de los Reyes de Castilla, vol. I, Biblioteca de Autores Españoles vol. 67. Madrid: Atlas, 1953, cap. 15, p. 21.

55 Arco y Garay, Ricardo. Sepulcros de la casa real de Castilla. Madrid: Consejo Superior de Investigaciones Científicas, 1954, p. 223.

56 Daumet, Mémoire, p. 120; cita AN, J601, n. 26 , lo publica en anexo 23.

57 La política exterior de Enrique II ya fue analizada hace años: SuÁrez Fernández, Luis. «Política internacional de Enrique II». Hispania, 1956, vol. 16, n. ${ }^{\circ}$ 62, pp. 16-129. 
En total en este periodo tenemos documentados un total de 131 embajadores, de los cuales tenemos datos de estudios de 30 y no tenemos de 101 . Es decir, un poco más del 22\%. Sin duda supone un incremento importante con respecto al anterior periodo. Además, empezamos a tener datos mucho más concretos sobre los embajadores. Para empezar, de la gran mayoría de ellos consta el grado concreto (doctor, licenciado, bachiller, maestro), y solo son tres los casos en los que podemos intuir la formación por el desempeño de funciones (como en el periodo anterior, son tres juristas). Además, de casi una cuarta parte del total (siete en concreto) conocemos la titulación específica: un doctor en decretos (Álvaro Martínez, enviado ante el papa Gregorio XI ${ }^{58}$ ), cuatro doctores en leyes (Juan Alfonso de Algana en tres ocasiones ${ }^{59}$ y Pedro López ${ }^{60}$ ), y dos maestros en Teología (Fernando de Illescas ${ }^{61}$ y Alfonso de Argüello ${ }^{62}$ ). Aún aparecen mencionados algunos embajadores de los que podemos suponer una formación como juristas por el cargo que desempeñan (dos oidores de la Audiencia que actúan en un total de tres ocasiones -Álvaro Martínez en $\operatorname{dos}^{63}$ y Ruy Bernal en una ${ }^{64}$ - a los que se ańade un tercero: Alfonso Rodríguez $^{65}$ ); pero sin duda es un ejemplo de cómo con el paso del tiempo vamos teniendo información más concreta. Aun así, la gran mayoría de los que conservamos datos (un total de 16 embajadores) son doctores, de los que no se indica o especifica claramente su especialidad, que podemos suponer legal (pero es solo una suposición).

El tercer periodo, el reinado de Juan II de Castilla, se ha separado porque, siendo uno de los más analizados ${ }^{66}$, sus datos estadísticos pueden distorsionar la visión de conjunto que tenemos a día de hoy. Y, efectivamente, si atendemos a los datos vemos que es así. Sobre este periodo tenemos documentados un total de 121 embajadores (no deja de

58 Serra Estellés, Javier. «El Cisma de Occidente y la Asamblea de Medina del Campo de 1380 1381 en el ms. lat. 11745 de la Biblioteca Nacional de Francia». Anthologica Annua, 2010, vol. 57, pp. 33303, en concreto p. 45; la titulación se refleja en Bibliothèque Nationale de France (en adelante BnF), ms. Latin 11745, fol. 99.

59 Daumet, Georges. Étude sur l'alliance de la France et de la Castille au XIV et XV siècles. Paris: Émile Bouillon, 1898, p. 44, citando AN, P2295; ibidem, p. 46, citando AN, J603, n. o 62bis; y DíAz Martín, Luis Vicente. «Los inicios de la política internacional de Castilla (1350-1410)». En RucQuoi, Adeline (coord.). Realidad e imágenes del poder. España a fines de la Edad Media. Valladolid: Ámbito, 1988, pp. 57-84, en concreto p. 72.

60 Díaz Martín, «Los inicios», p. 72.

61 Díaz Martín, «Los inicios», p. 78; cfr. Beltrán de Heredia, Cartulario, I, p. 154.

62 AGS, Estado-Castilla, leg. 1-1, fol. 53, documento publicado en Suárez Fernández, Luis. Castilla, el Cisma y la crisis conciliar (1378-1440). Madrid: Consejo Superior de Investigaciones Científicas, 1960, pp. 257-258.

63 Díaz Martín, «Los inicios», 73; y Suárez Fernández, Luis. Historia del reinado de Juan I de Castilla. Madrid: Universidad Autónoma, 1977, vol. I, pp. 205-306.

64 Daumet, Étude, p. 60; citando AN, J603, n. ${ }^{\circ}$ 69, anexo 41.

65 Díaz Martín, «Los inicios», p. 78

66 Sobre él han inicidido BeCEIRO PITA, «La importancia de la cultura» (aunque en él entran también embajadores aragoneses y portugueses, que aquí no son contemplados), así como ViLLARroel GonzÁlez, «Eclesiásticos en la diplomacia» (aunque en él solo se tienen en cuenta eclesiásticos) y CAÑAS Gálvez, Francisco de Paula. "La diplomacia castellana durante el reinado de Juan II: la participación de los letrados de la cancillería real en las embajadas regias». Anuario de Estudios Medievales, 2010, vol. 40, n. ${ }^{\circ}$, pp. 691-722. 
ser curioso que sean menos que en el inmediatamente anterior). Sin embargo, tenemos datos de los estudios de 70 de ellos, frente a 51 de los que no. Es decir, tenemos datos de casi un 58\% del total, lo que no tiene parangón en ninguno de los periodos anteriores y está muy por encima de la media total.

Nuevo cambio: de la inmensa mayoría de ellos conocemos los estudios y grado alcanzado de forma concreta. De hecho solo de dos de ellos sabemos que estudiaron en la universidad, sin llegar a saber nada más de sus estudios en estos momentos (Sancho de Rojas, el posterior obispo de Córdoba ${ }^{67}$ y Juan de Illescas, el posterior obispo de Sigüenza ${ }^{68}$ ). A estos habría que sumar dos posibles juristas, Diego López de Estúñiga, que ostentaba el cargo de justicia mayor ${ }^{69}$; y Juan Fernández de Toro, oidor ${ }^{70}$. Entre el resto nos encontramos a 17 bachilleres, 10 maestros, 11 licenciados y 29 doctores. Como vemos, priman los doctores, lo cual no deja de ser relevante (recordemos cómo definía Ayala al buen embajador).

Por último, el periodo del reinado de Enrique IV es del que menos datos tenemos. Su estudio está poco menos que iniciado y sus resultados se modificarán rápidamente en breve, pero se presentan por separado para evitar también distorsionar el periodo anterior. Tenemos datos de 15 embajadores y solo datos de estudios de tres de ellos (un $20 \%$ ), sin duda inferior a la media, pero podemos pensar que se debe a dos hechos funda-

\section{Con o sin datos por periodo}

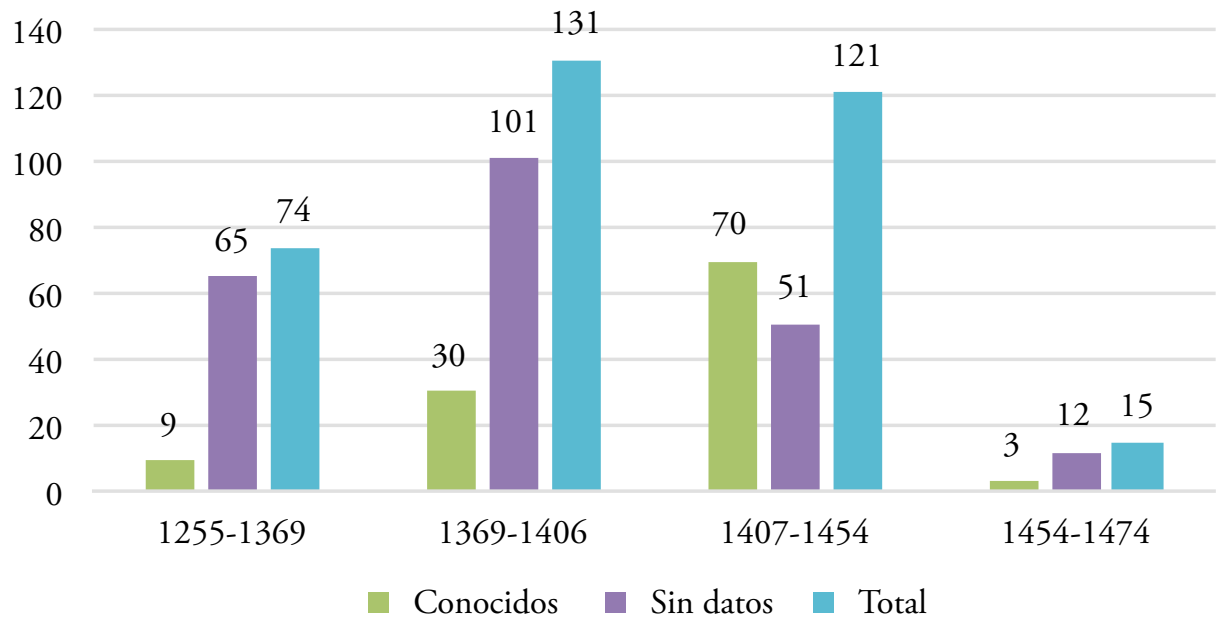

${ }^{67}$ Por ser oidor de la Audiencia, podemos suponer formación jurídica; pero de quien solo sabemos que estudió derecho canónico y filosofía en Valladolid Beltrán de Heredia, Bulario, I, p. 214.

68 Solo sabemos que estudió cánones en Salamanca, sin constar, de momento, su titulación. Díaz Martín, «Los inicios», p. 80. Sus estudios en Beltrán de Heredia, Cartulario, I, p. 186.

69 Introducimos la duda por ser un cargo que, posiblemente, se había convertido en un cargo puramente curial: Díaz Martín, «Los inicios», p. 81.

70 ACA, Cancillería, Registros, 2937, fols. 41v-45r. 
mentales: lo inicial del análisis y, como hipótesis que habría que comprobar, el hecho de que haya muchos nobles participando en esas misiones diplomáticas (son prácticamente la mitad). Eso sí, todos de los que conocemos su formación son doctores.

Así, si atendemos a la evolución cronológica y al número de embajadores, tanto de los que conocemos los datos como de los que no los tenemos, vemos que se produce un paulatino incremento del total, pero especialmente de aquellos de los que sí conocemos los datos (exceptuando el caso aún incompleto de Enrique IV).

La lógica evolutiva mostrada por la gráfica nos lleva a pensar que con un estudio en mayor profundidad de la diplomacia de Enrique IV los datos se igualarían (o al menos nos daría una razón lógica para el cambio). Es una línea a explorar en próximas investigaciones, sin duda. Sea como fuere, y obviando este reinado del que se incorporan menos datos, vemos una tendencia al incremento de las misiones diplomáticas, así como de los embajadores que sabemos que tuvieron formación universitaria.

\subsection{La formación de los que conocemos}

$\mathrm{Y}$, vista la tendencia al incremento de la formación de los embajadores, ¿qué podemos decir sobre cuáles fueron sus estudios? A este respecto los datos que nos ofrece el análisis son reveladores también.

Teniendo en cuenta todos los periodos en conjunto, nos encontramos con que los embajadores tenían mayoritariamente el grado de doctor (un 48\% de los casos conocidos), seguidos de bachilleres (16\%), maestros (14\%), licenciados (11\%) y en menor medida sabemos que eran juristas $(8 \%)$ o que habían estudiado en la universidad, sin saber exactamente qué (4\%).

\section{Grados de los embajadores}

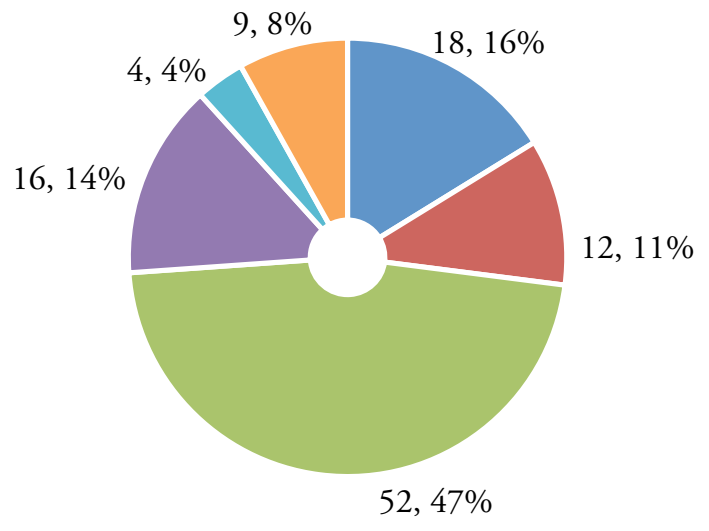

Bachiller $\square$ Licenciado $\square$ Doctor $\square$ Maestro $\square$ Estudios en universidad $\square$ Jurista 
Sin duda el gráfico es revelador. Una gran mayoría (de hecho casi la mitad) de los embajadores de los que tenemos conocimiento de sus estudios, tenían el más alto grado académico. Como hemos visto, además, el peso del doctorado se había ido incrementando con el paso del tiempo, lo cual nos muestra cómo la monarquía valoraba cada vez más este hecho a la hora de seleccionar a sus representantes diplomáticos. No deja de llamar la atención el hecho de que Ayala mismo mostrase la conciencia de que un buen embajador debía ser doctor, lo que nos habla tanto del valor que se daba al máximo grado académico, como de la importancia que tenía para la diplomacia. Es relevante, también, el hecho de que los datos sean semejantes a los obtenidos en estudios más parciales ${ }^{71}$.

$\mathrm{Si}$ atendemos al tipo de estudios los resultados vienen a confirmar también lo ya mostrado en otros trabajos de forma más parcial. Esto es así porque nos encontramos con que una importante mayoría de embajadores muestran una formación en derecho. Si sumamos todos aquellos que tienen una formación en derecho (sea civil o eclesiástico, y sea junto a otros estudios) suponen un total del $54 \%$ del total. Sí es cierto que dentro de estos tienen una cierta mayoría los que habían estudiado cánones: un 28\% de ellos tenían esta formación, frente a un 19\% que tenían formación en derecho civil (incluido el $4 \%$ de aquellos que tenían leyes y teología entre su formación). Aquellos cuya formación era en ambos derechos llegan a sumar un 7\%. No deja de sorprender también el 14\% de los formados solo en teología, materia en principio poco relacionada con la negociación política (a este respecto habría que tener en cuenta cuántos fueron embajadores ante el papa y cuántos iban acompañados por otros embajadores con otra formación más política). De cualquier forma, no deja de ser relevante que el segundo conjunto más amplio de todos es el de aquellos que no sabemos cuál era su especialidad. Esto demuestra que

\section{La formación de los embajadores}

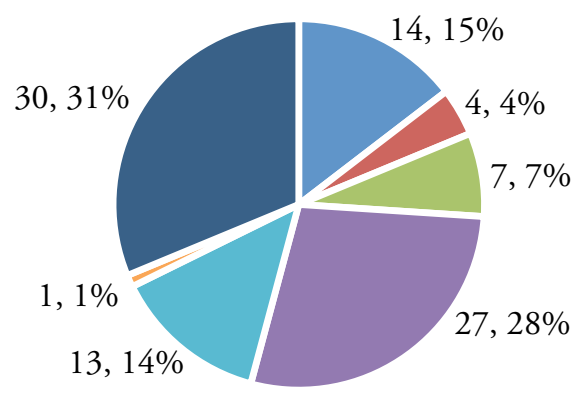

$\begin{array}{lll}\text { Derecho } & \text { Derecho y teología } \square \text { Ambos derechos } \\ \text { Decretos } \square \text { Teología } & \text { Medicina } \\ \text { No consta } & & \end{array}$

71 Cfr. Villarroel González, «Eclesiásticos en la diplomacia», p. 811. El orden de prioridad es el mismo, salvo por la alternancia entre bachilleres y maestros. 
la formación en sí era importante, al menos a la hora de ser mencionado en las fuentes, y no tanto el tipo de estudio (de hecho, ningún estudio específico supera en sus datos a los de bachilleres, licenciados o doctores sin asignación de especialidad).

En este caso sí nos encontramos con algún pequeño matiz frente a estudios más parciales anteriores, aunque se mantiene la primacía de la ley y, dato relevante, también de los decretistas frente a los especialistas en derecho civil $^{72}$, y es que es relevante la reducción de aquellos de los que no tenemos datos, fruto sin duda de la ampliación de la base estadística y de una ampliación de la base documental.

\section{Conclusiones}

Después de analizar los datos arrojados por la investigación podemos intentar ofrecer alguna respuesta a las preguntas planteadas al inicio del trabajo, aun manteniendo las cautelas iniciales y con la conciencia de que estos resultados pueden variar en cuanto a sus datos específicos y concretos (pese a que, como veremos, algunas respuestas empiezan a ser más firmes).

Si algo se puede afirmar a ciencia cierta es que, sin duda, el haber estudiado en las aulas universitarias no era, ni mucho menos, un requisito fundamental para la diplomacia castellana. De más de la mitad de los embajadores que tenemos documentados no se menciona nunca ningún tipo de formación. Indudablemente eso no quiere decir que no la tuviesen. Sin embargo, según avanza nuestro conocimiento de la diplomacia bajomedieval castellana podemos ver que en muchas ocasiones eso no es consecuencia de la falta de fuentes. Muchos nobles y prelados, que, como se puede observar, formaban parte de las embajadas, no habían necesitado ninguna formación para ascender a puestos de poder, tanto en la Iglesia como en sus propios linajes. Sin duda la pertenencia a un linaje garantizaba la posibilidad de colaborar con el rey (y por tanto ser nombrado embajador sin necesidad de estudios), o bien de ser elegido para un alto puesto de la jerarquía eclesiástica, lo que también facilitaba la posibilidad de esa cercanía al poder y de participación en la diplomacia ${ }^{73}$. Esto debería ser comprobado, empero, con un análisis prosopográfico detallado.

Sin embargo, sí es cierto que cada vez fue teniendo un peso mayor el poseer una formación superior, como podemos apreciar en el hecho de que con el paso del tiempo se vaya incrementando la cantidad de embajadores de los que conocemos su nivel y tipo de estudios. Con la lista, aún creciente (y más posiblemente en el futuro) de enviados diplomáticos castellanos podemos comprobar cómo cada vez hay más universitarios entre ellos y cada vez con mejor formación. Las noticias que nos llegan nos presentan un cuadro en el que paulatinamente cada vez iban teniendo más importancia aquellos que se habían formado en las aulas universitarias y, especialmente, aquellos vinculados al derecho.

72 Cfr. Villarroel González, «Eclesiásticos en la diplomacia», p. 812.

73 La vinculación de los prelados a los linajes nobiliarios fue analizada hace ańos en el caso castellano por DíAz IBÁŃEZ, Jorge. «La incorporación de la nobleza al alto clero en el reino de Castilla durante la Baja Edad Media». Anuario de Estudios Medievales, 2002, vol. 35, n. ${ }^{\circ}$ 3, pp. 557-604. 
El gran incremento de titulados al que asistimos desde finales del siglo xIV podemos considerarlo como la culminación de esa entrada de los letrados y universitarios en el servicio regio, movimiento que empieza a imponerse de forma natural en la diplomacia. No deja de ser llamativo el hecho de que los doctores fuesen aquellos que aparecen en más ocasiones. La más alta formación aparentemente fue preferida y de hecho había cierta conciencia de ello. Esto es especialmente relevante durante el reinado de Juan II, cuando ya los formados eran una mayoría de los embajadores y, dentro de ello, los doctores también fueron mayoritarios.

Se confirma también el hecho de que la formación en derecho era vista como ideal para el ejercicio de esta actividad, aunque no fuese la única ni, sobre todo, estrictamente necesaria. El hecho de que el derecho eclesiástico, al menos en su periodo pleno y bajomedieval, tuviese características muy semejantes al derecho civil (por sus formas de trabajo, organización y estudio, así como por las fuentes del mismo derecho) sin duda ayudó a que no obstase el ser especialista en derecho canónico para ello ${ }^{74}$. De hecho, se ha confirmado el dato, mostrado por análisis anteriores, de que los expertos en derecho canónico son aquellos que fueron más elegidos como embajadores (aun siendo una minoría), de entre aquellos de los que tenemos datos.

Nos queda, sin duda, mucho por saber, pero sin duda se puede afirmar que los universitarios, y en concreto los especialistas en derecho (en un sentido amplio) fueron teniendo cada vez un papel mayor en la diplomacia bajomedieval castellana. Podemos dudar del inicio de ese fenómeno, por la falta de datos sobre los más de cien primeros años, pero sin duda una visión amplia nos muestra que es un fenómeno creciente, en el que paulatinamente aquellos formados en esas materias iban teniendo cada vez más cabida en la diplomacia del reino. Lo que fuesen capaces de conseguir dependía ya de su propia capacidad, puesto que formación tenían.

\section{ANEXO: EMBAJADORES y ESTUdios}

\begin{tabular}{l|l|c|l|l}
\hline Nombre & CARGo & AÑo & Destino & Estudios \\
\hline Sancho & Arzobispo electo de Toledo & 1255 & Inglaterra & Estudió en París \\
\hline García Martínez de Toledo & Caballero & 1255 & Inglaterra & \\
\hline Sancho & Arzobispo electo de Toledo & 1255 & Francia & Estudió en París \\
\hline Viviano & Arcediano de Toledo & 1255 & Francia & \\
\hline García Martínez de Toledo & Caballero & 1255 & Francia & \\
\hline Rodrigo Fernández de Cardeńa & Caballero & 1255 & Francia & \\
\hline García Pérez & Arcediano de Marruecos & 1256 & Imperio & \\
\hline Juan Martínez & Obispo electo de Cádiz, franciscano & 1266 & Francia & \\
\hline
\end{tabular}

74 El mismo Corpus Iuris Civilis era una fuente fundamental del derecho canónico: Peset ReIG, Mariano y Alonso Romero, María Paz. «Las facultades de leyes». En Rodríguez-San Pedro Bezares, Luis Enrique (coord.). Historia de la Universidad de Salamanca. III-1. Saberes y confluencias. Salamanca: Universidad de Salamanca, 2005, pp. 21-73, en concreto págs. 22-23. 


\begin{tabular}{|c|c|c|c|c|}
\hline Nombre & Cargo & Año & Destino & Estudios \\
\hline Enrique el Toscano & Portero mayor de la corte imperial & 1266 & Francia & \\
\hline Fernando García & Arcediano de Niebla & 1269 & Francia & \\
\hline García Jofré & Caballero & 1269 & Francia & \\
\hline Pedro Cabezón & Notario & 1270 & Francia & \\
\hline Gutierre Garcés & Arcediano de Trevińo & 1277 & Aragón & \\
\hline Juan Arias & & 1277 & Aragón & \\
\hline Infante Manuel & Hermano del rey Alfonso & 1278 & Aragón & \\
\hline Fernán Pérez & Deán de Sevilla & 1278 & Aragón & \\
\hline Frédulo (según Eubel) & Obispo de Oviedo & 1278 & Roma & \\
\hline Pelayo Pérez & Arcediano de Astorga & 1280 & Aix en Provence & \\
\hline Belo de Arculis & Portero de la cámara del rey & 1280 & Aix en Provence & \\
\hline Pedro de Regio & Protonotario & 1280 & Aix en Provence & \\
\hline Frédulo (según Eubel) & Obispo de Oviedo & 1281 & Roma & \\
\hline Suero & Obispo de Cádiz & 1282 & Francia & \\
\hline Martín & Obispo de Calahorra & 1286 & Francia & \\
\hline Gómez García de Toledo & Abad de Valladolid, notario mayor de León & 1286 & Francia & \\
\hline Gonzalo & Arzobispo de Toledo & 1286 & Francia & \\
\hline Alonso & Obispo de Burgos & 1286 & Francia & \\
\hline Martín & Obispo de Calahorra & 1286 & Francia & \\
\hline Gómez García de Toledo & Abad de Valladolid, notario mayor de León & 1286 & Francia & \\
\hline Lope Díaz de Haro & Noble & 1287 & Aragón & \\
\hline Martín & Obispo de Astorga, notario mayor de León & 1288 & Francia & \\
\hline Rodrigo Velázquez & Canónigo de Santiago y Lugo & 1288 & Francia & \\
\hline Gonzalo & Arzobispo de Toledo & 1292 & Francia & \\
\hline Juan Fernández & Chantre de Palencia & 1294 & Francia & \\
\hline Nuńo & Obispo de Palencia & 1294 & Francia & \\
\hline Nicolás & Consejero y médico del rey & 1294 & Francia & Maestro, médico \\
\hline Pascasio Martínez & Juez de la corte & 1294 & Francia & Jurista \\
\hline Rodrigo Pérez de Atienza & Noble & 1305 & Francia & \\
\hline Nicolás & Médico del rey & 1305 & Francia & Maestro, médico \\
\hline Gonzalo de Hinojosa & Obispo de Burgos & 1317 & Francia & \\
\hline Martín Fernández de Portocarrero & Mayordomo mayor del infante Pedro & 1335 & Navarra & \\
\hline Gil de Albornoz & Arcediano de Calatrava & 1335 & Navarra & \\
\hline Fernán Sánchez & Notario mayor de Castilla & 1335 & Navarra & \\
\hline Fernán Sánchez & Caballero, notario mayor de Castilla & 1336 & Francia & \\
\hline Alfonso Martínez & Caballero & 1336 & Francia & \\
\hline Hugo de Alcana & Caballero & 1336 & Francia & \\
\hline Fernán Rodríguez de Villalobos & Caballero & 1337 & Portugal & \\
\hline Diego Ramírez de Guzmán & Luego obispo de León & 1340 & \begin{tabular}{|l|} 
Reunión \\
internacional
\end{tabular} & \\
\hline
\end{tabular}




\begin{tabular}{|c|c|c|c|c|}
\hline Nombre & CARGO & Año & Destino & Estudios \\
\hline Juan Hurtado de Mendoza & Noble & 1340 & \begin{tabular}{|l|} 
Reunión \\
internacional
\end{tabular} & \\
\hline Alfonso Fernández Coronel & Noble & 1342 & Papado & \\
\hline Albar García de Ibles & Juez de la casa del rey & 1342 & Papado & Jurista \\
\hline Gil de Albornoz & Arzobispo de Toledo & 1342 & Francia & \\
\hline Alfonso Ortiz Calderón & Prior de san Juan & 1342 & Papado & \\
\hline Gómez Fernández de Soria & \begin{tabular}{|l} 
Jurista \\
\end{tabular} & 1342 & Portugal & Jurista \\
\hline Juan Estébanez de Castellanos & Canciller & 1342 & Portugal & \\
\hline García Fernández de Boneso & Caballero & 1344 & Papado & \\
\hline Rodrigo Alonso de Logrońo & Abad de san Miguel de Alfaro & 1344 & Papado & \\
\hline Gonzalo & Obispo de Sigüenza & 1345 & Francia & \\
\hline Ferrán Sánchez de Valladolid & & 1345 & Francia & \\
\hline Juan Hurtado de Mendoza & Caballero & 1345 & Inglaterra & \\
\hline Gil de Albornoz & Arzobispo de Toledo & 1346 & Francia & \\
\hline Alfonso Fernández Coronel & & 1346 & Francia & \\
\hline Fernán Sánchez & & 1346 & Francia & \\
\hline Juan Martínez de Madrid & & 1347 & Inglaterra & \\
\hline Juan Sánchez de las Roelas & Obispo electo de Segovia & 1351 & Francia & \\
\hline Alvar García de Albornoz & & 1351 & Francia & \\
\hline Gómez Fernández de Soria & Gobernador de Sevilla & 1358 & Portugal & \\
\hline Samuel Levi & Tesorero del rey & 1358 & Portugal & \\
\hline García Gutiérrez Tello & Juez de Sevilla & 1358 & Portugal & Jurista \\
\hline Martín López de Córdoba & Maestre de Alcántara & 1362 & Inglaterra & \\
\hline Diego Sánchez de Terrazas & \begin{tabular}{|l|} 
Caballero \\
\end{tabular} & 1362 & Inglaterra & \\
\hline Álvaro Sánchez de Cuéllar & & 1362 & Inglaterra & Bachiller en decretos \\
\hline Sancho & Obispo de Oviedo & 1364 & Navarra & \\
\hline Ruy Bernal & & 1364 & Navarra & \\
\hline Juan & Obispo de Sigüenza & 1368 & Aragón & \\
\hline Lope Fernández Gaytán & & 1368 & Aragón & \\
\hline Juan Gutiérrez & Deán de Segovia & 1369 & Inglaterra & \\
\hline Álvaro García de Albornoz & Mayordomo del rey Enrique II & 1370 & Aragón & \\
\hline Domingo de Arroyuelo & Obispo de Burgos & 1370 & Aragón & \\
\hline Juan & Obispo de Badajoz, canciller mayor & 1371 & Portugal & \\
\hline Juan Fernández & Camarero del infante Juan & 1371 & Portugal & \\
\hline León de Bocanegra & Almirante (maiorem capitaneum maris) & 1371 & Portugal & \\
\hline Alfonso Pérez de Guzmán & Señor de Gibraleón & 1371 & Portugal & \\
\hline Alvar García de Albornoz & & 1371 & Aragón & \\
\hline Domingo de Arroyuelo & Obispo de Burgos & 1371 & Aragón & \\
\hline Diego López Pacheco & Noble portugués & 1372 & Portugal & \\
\hline
\end{tabular}




\begin{tabular}{|c|c|c|c|c|}
\hline Nombre & Cargo & Año & DESTINO & Estudios \\
\hline Juan García Manrique & Obispo de Sigüenza & 1372 & Portugal & \\
\hline Alfonso & Obispo de Salamanca & 1373 & Aragón & \\
\hline Juan Ramírez de Arellano & Noble & 1373 & Aragón & \\
\hline Pedro Fernández de Velasco & Camarero mayor del rey & 1374 & Francia & \\
\hline Juan Ramírez de Arellano & Caballero & 1374 & Francia & \\
\hline Fernán Sánchez Tovar & Almirante & 1374 & Portugal & \\
\hline Alfonso & Obispo de Salamanca & 1374 & Aragón & \\
\hline Juan Ramírez de Arellano & Noble & 1374 & Aragón & \\
\hline Pedro Fernández de Velasco & Camarero mayor del rey & 1375 & \begin{tabular}{|l|} 
Reunión \\
internacional
\end{tabular} & \\
\hline Alfonso Barrosa & Obispo de Salamanca & 1375 & \begin{tabular}{|l|} 
Reunión \\
internacional
\end{tabular} & \\
\hline Gutierre Gómez & Obispo de Palencia & 1375 & Aragón & \\
\hline Juan de Trastámara & Infante de Castilla & 1375 & Aragón & \\
\hline Gutierre & Obispo de Palencia & 1375 & Aragón & \\
\hline Martín & Obispo de Plasencia & 1375 & Aragón & \\
\hline Juana & Reina de Castilla & 1375 & Aragón & \\
\hline Pedro González de Velasco & Camarero mayor del rey & 1375 & Aragón & \\
\hline Pedro González de Mendoza & Alférez mayor & 1375 & Aragón & \\
\hline Fernán Pérez de Andrade & Noble & 1376 & Portugal & \\
\hline Ruy Bernal & Arcediano de Cuenca? & 1376 & Papado & \\
\hline Pedro Fernández & Arcediano de Trevińo & 1376 & Papado & \\
\hline Juan Ramírez de Arellano & Noble & 1376 & \begin{tabular}{|l} 
Papado \\
\end{tabular} & \\
\hline Pedro López de Ayala & Noble & 1376 & Aragón & \\
\hline Pedro López de Ayala & Noble & 1378 & Francia & \\
\hline Ruy Bernal & & 1378 & Francia & \\
\hline Pedro Fernández de Trevińo & Arcediano de Trevińo & 1378 & Francia & \\
\hline Álvaro Martínez & Luego obispo de Cuenca & 1378 & Papado & Doctor en decretos \\
\hline Nicolás de Viedma & Obispo de Cuenca & 1378 & Papado & \\
\hline Juan de Trastámara & Infante de Castilla & 1379 & Navarra & \\
\hline Pedro López de Ayala & \begin{tabular}{|l|} 
Noble \\
\end{tabular} & 1380 & Francia & \\
\hline Juan Alfonso de Algana & & 1380 & Francia & Doctor en leyes \\
\hline Ruy Bernal & & 1380 & Francia & \\
\hline Pedro López & & 1380 & Francia & Doctor \\
\hline Ruy Bernal & & 1380 & Papado & \\
\hline Fernando de Illescas & Confesor del rey & 1380 & Papado & \\
\hline Î́nigo Ortiz de Stúńiga & & 1380 & Portugal & \\
\hline Diego López de Stúńiga & & 1380 & Aragón & \\
\hline Pedro Fernández & Arcediano de Treviño & 1380 & Aragón & \\
\hline
\end{tabular}




\begin{tabular}{|c|c|c|c|c|}
\hline Nombre & Cargo & Año & Destino & Estudios \\
\hline Pedro López de Ayala & Alférez del rey & 1381 & Francia & \\
\hline Juan Alfonso de Algana & Deán de Burgos & 1381 & Francia & Doctor en leyes \\
\hline Ruy Bernal & & 1381 & Francia & \\
\hline Pedro López & & 1381 & Francia & Doctor \\
\hline Pascasio García & Deán de Orense & 1381 & Aragón & \\
\hline Álvaro & Obispo de Zamora & 1381 & Aragón & \\
\hline Juan García Manrique & Arzobispo de Compostela & 1382 & Portugal & \\
\hline Alfonso López de Tejada & & 1383 & Portugal & \\
\hline Pedro López de Ayala & Noble & 1384 & Francia & \\
\hline Juan Alfonso de Algana & & 1384 & Francia & Doctor en leyes \\
\hline Ruy Bernal & & 1384 & Francia & \\
\hline Pedro López & & 1384 & Francia & Doctor \\
\hline Pedro Fernández de Velasco & & 1384 & Portugal & \\
\hline Tello González & & 1384 & Papado & \\
\hline Juan Serrano & Prior de Guadalupe & 1386 & Lancaster & \\
\hline Pedro López & Arcediano de Alcaraz & 1387 & Francia & \\
\hline Fernando de Illescas & Confesor del rey & 1387 & Lancaster & \\
\hline Pedro Sánchez del Castillo & & 1387 & Lancaster & \\
\hline Alvar Martínez de Villarreal & & 1387 & Lancaster & Doctor \\
\hline Pedro López de Ayala & Noble. Enviado a Bayona ante Juan de Gante & 1389 & Lancaster & \\
\hline Pedro Fernández de Frías & Obispo de Osma & 1389 & Lancaster & \\
\hline Fernando de Illescas & Confesor del rey & 1389 & Lancaster & \\
\hline Álvaro Martínez & Oidor de la Audiencia & 1389 & Lancaster & Jurista \\
\hline Pedro López & Arcediano de Toledo & 1389 & Lancaster & Doctor \\
\hline Álvaro Martínez & Oidor & 1389 & Internacional & Jurista \\
\hline Pedro López & Arcediano de Toledo & 1389 & Internacional & Doctor \\
\hline Fernando de Illescas & Confesor del rey & 1389 & Portugal & \\
\hline Pedro Sánchez del Castillo & & 1389 & Portugal & \\
\hline Alfonso Sánchez & & 1389 & Portugal & \\
\hline Alfonso de Egea & Obispo de Zamora & 1391 & Francia & \\
\hline Diego Fernández & Mariscal & 1391 & Francia & \\
\hline Ruy Bernal & Oidor de la Audiencia & 1391 & Francia & Jurista \\
\hline Pedro López de Ayala & Noble & 1392 & Portugal & \\
\hline Antón Sánchez & & 1392 & Portugal & Doctor \\
\hline Juan Serrano & Antiguo prior de Guadalupe & 1392 & Portugal & \\
\hline Lope de Mendoza & Obispo de Mondońedo & 1394 & Francia & \\
\hline Fernando de Illescas & Confesor de Juan I & 1394 & Francia & \\
\hline Alfonso Rodia & & 1394 & Francia & Doctor en leyes \\
\hline Pedro López de Ayala & Noble & 1395 & Francia & \\
\hline
\end{tabular}




\begin{tabular}{|c|c|c|c|c|}
\hline Nombre & CARGO & AÑo & Destino & Estudios \\
\hline Domingo Fernández & Tesorero de Oviedo & 1395 & Francia & \\
\hline Vicente Arias de Balboa & Arcediano de Toledo & 1395 & Francia & \\
\hline Antón Sánchez & & 1395 & Portugal & Doctor \\
\hline Pedro Martínez & & 1395 & Portugal & \\
\hline Álvaro de Isorna & Obispo de Cuenca & 1395 & Francia & Licenciado \\
\hline García González de Herrera & Mariscal & 1396 & Portugal & \\
\hline Antón Sánchez & & 1396 & Portugal & Doctor \\
\hline Pedro Sánchez & & 1396 & Portugal & \\
\hline Pedro López de Ayala & Noble & 1396 & Francia & \\
\hline Lope de Mendoza & Obispo de Mondońedo & 1396 & Francia & \\
\hline Bertrand de Malmont & & 1396 & Francia & \\
\hline Fernando de Illescas & Confesor del rey & 1396 & Francia & \\
\hline Alfonso Rodríguez & & 1396 & Francia & Doctor \\
\hline ?? & & 1397 & Inglaterra & \\
\hline Alfonso Rodríguez de Salamanca & Catedrático de Salamanca & 1397 & Papado & Doctor \\
\hline Fernando de Illescas & Secretario de Pedro Tenorio, confesor del rey & 1398 & Papado & Maestro en teología \\
\hline Lorenzo Suárez de Figueroa & Maestre de Santiago & 1399 & Portugal & \\
\hline Ruy López Dávalos & Adelantado mayor de Murcia & 1399 & Portugal & \\
\hline Pedro & Obispo de Palencia & 1399 & Portugal & \\
\hline Diego Fernández & Mariscal & 1399 & Portugal & \\
\hline Fernán Pérez de Ayala & Merino mayor de Guipúzcoa & 1401 & Francia & \\
\hline Fernando ¿̨de Illescas? & Confesor del rey & 1401 & Francia & \\
\hline Alfonso Rodríguez de Salamanca & & 1401 & Papado & Doctor \\
\hline Alfonso de Argüello & & 1401 & Papado & \\
\hline Payo Gómez de Sotomayor & & 1401 & Tamerlán & \\
\hline Hernán Sánchez de Palazuelos & & 1401 & Tamerlán & \\
\hline Ruy López Dávalos & Condestable de Castilla & 1402 & Portugal & \\
\hline Pedro Fernández de Cámara & Secretario real & 1402 & Inglaterra & Doctor \\
\hline Gonzalo Moro & & 1403 & Inglaterra & Doctor \\
\hline Pedro Fernández de Cámara & Secretario real y contador & 1403 & Papado & Doctor \\
\hline Pedro Yánez & Secretario del Consejo & 1403 & Papado & Doctor \\
\hline Ruy González de Clavijo & & 1403 & Tamerlán & \\
\hline Alonso Páez de Santa María & Dominico & 1403 & Tamerlán & Maestro en teología \\
\hline Gómez de Salazar & & 1403 & Tamerlán & \\
\hline Juan Alfonso de Madrid & & 1404 & Papado & \\
\hline Gonzalo Moro & & 1404 & Papado & Doctor \\
\hline Juan Alfonso de Madrid & & 1405 & Papado & \\
\hline Alfonso de Egea & Arzobispo de Sevilla & 1405 & Papado & \\
\hline Alfonso de Argüello & Obispo de León & 1405 & Papado & Maestro en teología \\
\hline
\end{tabular}




\begin{tabular}{|c|c|c|c|c|}
\hline Nombre & CARGO & AÑo & Destino & Estudios \\
\hline Fernán Pérez de Ayala & Merino mayor de Guipúzcoa & 1405 & Papado & \\
\hline Alfonso de Alcocer & Confesor del rey & 1405 & Papado & \\
\hline Alfonso de Alcocer & Confesor del rey & 1406 & Papado & \\
\hline Alfonso de Estúñiga & & 1406 & Papado & \\
\hline Alfonso Rodríguez & Jurista & 1406 & Papado & Jurista \\
\hline Juan de Illescas & Obispo de Sigüenza & 1407 & Portugal & \begin{tabular}{|l|}
$\begin{array}{l}\text { Estudió } \\
\text { en Salamanca }\end{array}$ \\
\end{tabular} \\
\hline Pedro Villegas & & 1407 & Portugal & \\
\hline Pedro Sánchez del Castillo & & 1407 & Portugal & Doctor \\
\hline Pedro Venegas & Alcalde mayor de Córdoba & 1407 & Portugal & \\
\hline Juan Rodríguez de Villalón & Prior de Medina & 1407 & Papado & Bachiller en decretos \\
\hline Fernando García & Capellán de la reina & 1407 & Papado & Bachiller \\
\hline Pedro Fernández & Arcediano del Alcor & 1407 & Papado & \\
\hline Diego López & Arcediano de Deza & 1407 & Papado & \\
\hline Juan Rodríguez de Villalón & Arcediano de Gordón, prior de Usillos & 1408 & Portugal & Bachiller en decretos \\
\hline Juan Rodríguez de Villalón & Arcediano de Gordón, prior de Usillos & 1408 & Castilla & Bachiller en decretos \\
\hline Fadrique de Trastámara & & 1408 & Castilla & \\
\hline Juan & Obispo de Sigüenza & 1408 & Castilla & \\
\hline Enrique de Monte Rotundo & & 1408 & Castilla & \\
\hline Gutierre Gómez de Toledo & Arcediano de Guadalajara & 1408 & Castilla & \\
\hline Perafán de Ribera & & 1408 & Castilla & \\
\hline Diego Fernández de Córdoba & & 1408 & Castilla & \\
\hline Juan Rodríguez de Salamanca & & 1408 & Castilla & Doctor \\
\hline Pero Yáñez & & 1408 & Castilla & Doctor \\
\hline Fernán Gutiérrez de Vega & Repostero mayor del infante Fernando & 1409 & Aragón & \\
\hline Juan González de Acevedo & & 1409 & Aragón & Doctor \\
\hline Fernando Martínez Dávalos & & 1409 & Papado & \\
\hline Gonzalo Moro & & 1410 & Inglaterra & Doctor en leyes \\
\hline Sancho de Rojas & Obispo de Palencia & 1410 & Aragón & \\
\hline Diego López de Stúńiga & Justicia mayor & 1410 & Aragón & Jurista \\
\hline Pedro Sánchez del Castillo & Oidor, consejero & 1410 & Aragón & Doctor \\
\hline Diego de Anaya & Obispo de Cuenca, consejero real & 1416 & \begin{tabular}{|l|} 
Concilio \\
Constanza \\
\end{tabular} & Bachiller en decretos \\
\hline Fernando Pérez de Ayala & Merino mayor de Guipúzcoa, consejero & 1416 & \begin{tabular}{|l|} 
Concilio \\
Constanza \\
\end{tabular} & \\
\hline Juan Rodríguez de Villalón & Obispo de Badajoz & 1416 & \begin{tabular}{|l|} 
Concilio \\
Constanza \\
\end{tabular} & Bachiller en decretos \\
\hline Martín Fernández & Vasallo regio & 1416 & \begin{tabular}{|l|} 
Concilio \\
Constanza \\
\end{tabular} & \\
\hline Fernando de Illescas & Confesor del rey & 1416 & \begin{tabular}{|l} 
Concilio \\
Constanza
\end{tabular} & \\
\hline
\end{tabular}




\begin{tabular}{|c|c|c|c|c|}
\hline NOMBRE & Cargo & AÑo & Destino & Estudios \\
\hline Fernando Martínez Dávalos & Deán de Segovia, oidor de la Audiencia & 1416 & \begin{tabular}{|l|} 
Concilio \\
Constanza \\
\end{tabular} & Doctor en decretos \\
\hline Diego Fernández de Valladolid & Deán de Palencia & 1416 & \begin{tabular}{|l|l|} 
Concilio \\
Constanza \\
\end{tabular} & Doctor en decretos \\
\hline Luis de Valladolid & Dominico & 1416 & \begin{tabular}{|l|} 
Concilio \\
Constanza \\
\end{tabular} & Lcdo. en teología \\
\hline Juan Fernández de Rupello & & 1416 & \begin{tabular}{|l|} 
Concilio \\
Constanza \\
\end{tabular} & Doctor en decretos \\
\hline Pedro Fernández de Cámara & Secretario real, arcediano de Grado & 1416 & \begin{tabular}{|l|} 
Concilio \\
Constanza \\
\end{tabular} & Doctor \\
\hline Juan de Cervantes & Arcediano de Calatrava & 1417 & Papado & $\begin{array}{l}\text { Bachiller en leyes, } \\
\text { maestro en teología }\end{array}$ \\
\hline Pedro Fernández de Cámara & Secretario real, capellán apostólico & 1417 & Papado & Doctor \\
\hline Juan de Cervantes & Arcediano de Calatrava & 1419 & Papado & $\begin{array}{l}\text { Bachiller en leyes, } \\
\text { maestro en teología }\end{array}$ \\
\hline Diego de Anaya & Arzobispo de Sevilla & 1419 & Francia & Bachiller en decretos \\
\hline Rodrigo Bernal & Arcediano de Alarcón & 1419 & Francia & \\
\hline Gutierre de Toledo & Arcediano de Guadalajara & 1420 & Papado & \\
\hline Alonso de Pimentel & & 1421 & Francia & \\
\hline Alfonso de Cartagena & Deán de Segovia & 1421 & Portugal & Doctor en leyes \\
\hline Juan Alfonso de Zamora & Secretario real & 1421 & Portugal & Bachiller en decretos \\
\hline Álvaro Núńez de Isorna & Obispo de Cuenca & 1421 & Papado & Lcdo. en decretos \\
\hline Diego Bedán & Obispo de Cartagena & 1422 & Aragón & Maestro en teología \\
\hline Diego Rodríguez & & 1422 & Aragón & Doctor \\
\hline Luis de Valladolid & Confesor regio, dominico & 1422 & Aragón & Lcdo. en teología \\
\hline García Alonso de Olloa & Caballero de Toro & 1422 & Aragón & \\
\hline Juan Alfonso de Mella & $\begin{array}{l}\text { Cantor de Coria, canónigo de Zamora y } \\
\text { Salamanca } \\
\end{array}$ & 1423 & Papado & Doctor en decretos \\
\hline Juan Martínez Contreras & Arzobispo de Toledo, consejero real & 1423 & Papado & \begin{tabular}{|l|} 
Lcdo. en decretos, \\
bachiller en leyes \\
\end{tabular} \\
\hline Juan de Cervantes & Arcediano de Sevilla & 1423 & Concilio de Siena & \begin{tabular}{|l} 
Bachiller en leyes, \\
maestro en teología
\end{tabular} \\
\hline Juan Martínez Contreras & Arzobispo de Toledo, consejero real & 1423 & Concilio de Siena & \begin{tabular}{|l|} 
Lcdo. en decretos, \\
bachiller en leyes \\
\end{tabular} \\
\hline $\begin{array}{l}\text { Pedro Alfonso de Valladolid (o } \\
\text { García de Ezcaray) }\end{array}$ & Abad de Alfaro, capellán regio & 1423 & Concilio de Siena & Lcdo. en decretos \\
\hline Ruy García de Villaquirán & Canónigo de Toledo & 1423 & Papado & Doctor en leyes \\
\hline Rodrigo de Perea & Mayordomo regio & 1423 & Papado & \\
\hline Sancho de Rojas & Oidor de la Audiencia & 1423 & Papado & $\begin{array}{l}\text { Estudios en } \\
\text { universidad } \\
\end{array}$ \\
\hline Diego Bedán & Obispo de Cartagena, consejero real & 1424 & Aragón & Maestro en teología \\
\hline
\end{tabular}




\begin{tabular}{|c|c|c|c|c|}
\hline NomBre & CARGO & Año & Destino & Estudios \\
\hline Diego Rodríguez & & 1424 & Aragón & Doctor \\
\hline Enrico Schulte & Secretario real & 1424 & Concilio de Siena & \\
\hline Sancho de Rojas & Oidor de la Audiencia, obispo de Astorga & 1424 & Concilio de Siena & \\
\hline Alfonso & & 1424 & Concilio de Siena & \\
\hline Sancho López de Vesco & Obispo de Salamanca, consejero real & 1424 & Aragón & \\
\hline Juan Hurtado de Mendoza & Señor de Almazán, consejero real & 1424 & Aragón & \\
\hline García López de Trujillo & & 1424 & Aragón & Doctor \\
\hline Francisco de Soria & Franciscano & 1429 & Navarra & \\
\hline Sancho de Rojas & Obispo de Astorga & 1429 & Navarra & \\
\hline Pedro de Bocanegra & Deán de Cuenca & 1429 & Navarra & Lcdo. en leyes \\
\hline Juan Álvarez de Toledo & $\begin{array}{l}\text { Canónigo de Palencia y Toledo, propuesto } \\
\text { arcediano de Madrid, hermano del señor de } \\
\text { Oropesa }\end{array}$ & 1429 & Papado & Bachiller en decretos \\
\hline Sancho de Rojas & Obispo de Astorga & 1430 & Inglaterra & \\
\hline Juan del Corral & Franciscano & 1430 & Inglaterra & Maestro en teología \\
\hline Remón & Monje del Císter & 1431 & Armagnac & \\
\hline Juan Martínez Contreras & Arzobispo de Toledo, consejero real & 1431 & Aragón & $\begin{array}{l}\text { Lcdo. en decretos, } \\
\text { bachiller en leyes }\end{array}$ \\
\hline Juan Hurtado de Mendoza & Señor de Almazán, consejero real & 1431 & Aragón & \\
\hline Fernando González Dávila & Oidor y refrendario, del Consejo & 1431 & Aragón & Doctor \\
\hline Pedro González del Castillo & Oidor y del consejo & 1431 & Aragón & Doctor \\
\hline Juan Fernández de Toro & Oidor & 1431 & Aragón & \\
\hline Pedro de Bocanegra & Capellán del rey, deán de Cuenca & 1431 & Aragón & \\
\hline Martín de Vargas & Reformador del Císter & 1431 & Aragón & Maestro en teología \\
\hline Juan de Torquemada & Dominico & 1432 & Concilio Basilea & $\begin{array}{l}\text { Doctor en teología } \\
\text { y derecho? }\end{array}$ \\
\hline Juan de Cervantes & Obispo de Tuy & 1432 & Concilio Basilea & \begin{tabular}{|l|} 
Bachiller en leyes, \\
maestro en teología
\end{tabular} \\
\hline Rodrigo Gutiérrez de Barcenilla & Secretario del rey, arcediano de Toro & 1432 & Papado & \\
\hline Juan Alfonso de Mella & $\begin{array}{l}\text { Arcediano de Madrid, capellán pontificio, } \\
\text { oidor del Sacro Palacio }\end{array}$ & 1433 & Papado & Lcdo. en decretos \\
\hline Juan Carrillo & Arcediano de Cuenca & 1434 & Francia & \\
\hline Alfonso de Cartagena & Deán de Santiago, obispo de Burgos & 1434 & Concilio Basilea & Doctor en leyes \\
\hline Álvaro Núnez de Isorna & Obispo de Cuenca & 1434 & Concilio Basilea & Lcdo. en decretos \\
\hline Juan del Corral & Franciscano & 1434 & Concilio Basilea & Maestro en teología \\
\hline Juan Alfonso de Zamora & Porcionario de León, ha sido secretario real & 1434 & Concilio Basilea & Bachiller en decretos \\
\hline Juan González de la Maina & Secretario real, maestrescuela de Sigüenza & 1434 & Concilio Basilea & Bachiller en decretos \\
\hline Luis Álvarez de Paz & Oidor de la Audiencia real & 1434 & Concilio Basilea & Doctor en decretos \\
\hline Lope de Galdo & Provincial dominico & 1434 & Concilio Basilea & \\
\hline
\end{tabular}




\begin{tabular}{|c|c|c|c|c|}
\hline NoMBRE & CARGO & AÑo & Destino & Estudios \\
\hline Gil Fernández de Alfaro & & 1434 & Papado & \\
\hline Gonzalo de Santa María & Obispo de Plasencia & 1436 & Concilio Basilea & Doctor en decretos \\
\hline Pedro de Bocanegra & Deán de Cuenca & 1436 & Papado & Lcdo. en leyes \\
\hline Vasco Ramírez de Guzmán & Arcediano de Toledo & 1436 & Francia & \\
\hline Alfonso de Cartagena & Obispo de Burgos & 1438 & Imperio & Doctor en leyes \\
\hline Rodrigo Sánchez de Arévalo & Capellán del rey & 1438 & Imperio & Bachiller en leyes \\
\hline Alfonso González de Herrera & Abad de Santa Colomba (Sigüenza) & 1439 & Papado & Bachiller en decretos \\
\hline Alfonso de Cartagena & Obispo de Burgos & 1440 & Navarra & Doctor en leyes \\
\hline Alfonso de Velasco & Deán de Zamora, protonotario apostólico & 1440 & Navarra & \\
\hline Rodrigo Sánchez de Arévalo & Secretario real, arcediano de Treviño & 1441 & Papado & \begin{tabular}{|l|}
$\begin{array}{l}\text { Bachiller en ambos } \\
\text { derechos }\end{array}$ \\
\end{tabular} \\
\hline Alfonso González de Herrera & Abad de Santa Colomba (Sigüenza) & 1442 & Papado & Bachiller en decretos \\
\hline Rodrigo Sánchez de Arévalo & Secretario real, arcediano de Treviño & 1442 & Imperio & \begin{tabular}{|l|} 
Bachiller en ambos \\
derechos
\end{tabular} \\
\hline Alfonso Sánchez de Madrigal & Canónigo de Salamanca, capellán regio & 1443 & Aragón & \begin{tabular}{|l|} 
Maestro en Artes y \\
bachiller en teología
\end{tabular} \\
\hline Fortún Velázquez de Cuéllar & Arcediano de Cuéllar & 1443 & Papado & \begin{tabular}{|l|} 
Doctor en ambos \\
derechos
\end{tabular} \\
\hline Pedro de Cervantes & Arcediano de Briviesca, capellán real & 1444 & Aragón & Bachiller en decretos \\
\hline Juan Alfonso de Cuenca & $\begin{array}{l}\text { Abad de Alcalá la Real, consejero real, capellán } \\
\text { real }\end{array}$ & 1444 & Aragón & \\
\hline Diego de Valera & & 1444 & Francia & \\
\hline Alfonso de Brigianos & Caballero de Álvaro de Luna & 1444 & Francia & \\
\hline Î́nigo de Arceo & & 1444 & Francia & \\
\hline Juan García & Canónigo de Palencia, capellán real & 1445 & Papado & \\
\hline Alfonso de Segura & Deán de Sevilla & 1445 & Portugal & Doctor en decretos \\
\hline Juan Alfonso de Cuenca & $\begin{array}{l}\text { Abad de Alcalá la Real, consejero real, capellán } \\
\text { real }\end{array}$ & 1445 & Aragón & \\
\hline Alfonso de Segura & Deán de Toledo, oidor del Sacro Palacio & 1447 & Portugal & Doctor en decretos \\
\hline Francisco de Toledo & Deán de Toledo & 1449 & Papado & \\
\hline Juan de Torquemada & $\begin{array}{l}\text { Cardenal de San Sixto (un ańo antes renunció } \\
\text { al obispado de Orense) }\end{array}$ & 1449 & Papado & Doctor en teología \\
\hline Ínigo de Arceo & & 1450 & Francia & \\
\hline Luis González de Atienza & Secretario real, maestrescuela de Sigüenza & 1451 & Aragón & \\
\hline Luis González de Atienza & Secretario real, maestrescuela de Sigüenza & 1453 & Papado & \\
\hline Luis González de Atienza & Secretario real, maestrescuela de Sigüenza & 1454 & Aragón & \\
\hline Juan Manuel & Guarda mayor del rey & 1454 & Francia & \\
\hline Fortún Velázquez de Cuéllar & Deán de Segovia, protonotario apostólico & 1454 & Francia & \\
\hline Juan Manuel & Guarda mayor & 1454 & Francia & \\
\hline Alonso de Paz & & 1454 & Francia & Doctor en leyes \\
\hline
\end{tabular}


LA FORMACIÓN DE LOS DIPLOMÁTICOS EN LA CASTILLA BAJOMEDIEVAL

144 ÓSCAR VILLARROEL GONZÁLEZ

\begin{tabular}{l|l|l|l|l}
\hline NomBre & CARGo & AÑo & Destino & Estudios \\
\hline Luis González de Atienza & Secretario real, deán de Córdoba & 1456 & Aragón & \\
\hline Fortún Velázquez de Cuéllar & Consejero del rey & 1456 & Francia & \\
\hline Juan Manuel & Consejero del rey & 1456 & Francia & \\
\hline Alfonso Álvarez & Consejero del rey & 1456 & Francia & \\
\hline Juan Manuel & & 1457 & Francia & \\
\hline Alfonso Álvarez & & 1457 & Francia & Doctor \\
\hline Luis González de Atienza & Protonotario apostólico & 1466 & Francia & \\
\hline Ínigo de Arceo & & 1466 & Francia & \\
\hline Alonso de Palenzuela & Obispo de Ciudad Rodrigo & 1467 & Inglaterra & \\
\hline Luis González de Atienza & Protonotario apostólico, deán de Córdoba & 1470 & Francia & \\
\hline
\end{tabular}

\section{REFERENCIAS BIBLIOGRÁFICAS}

Arco y Garay, Ricardo. Sepulcros de la casa real de Castilla. Madrid: Consejo Superior de Investigaciones Científicas, 1954.

Ballesteros Beretta, Antonio. Alfonso X el Sabio. Barcelona: Salvat, 1963.

BarCala Muñoz, Andrés. «Las universidades españolas durante la Edad Media». Anuario de Estudios Medievales, 1985, vol. 15, pp. 83-126.

Beceiro Pita, Isabel. «La importancia de la cultura en las relaciones peninsulares (siglo Xv)». Anuario de Estudios Medievales, 1999, vol. 29, pp. 79-104.

Beltrán de Heredia, Vicente. Bulario de la Universidad de Salamanca. 3 vols. Salamanca: Ediciones Universidad de Salamanca, 1966-1967.

Beltrán de Heredia, Vicente. Cartulario de la Universidad de Salamanca. Salamanca: Ediciones Universidad de Salamanca, 1970, vol. 1.

Bizzarri, Hugo Óscar (ed.). Secreto de los secretos = Poridat de las poridades: versiones castellanas del pseudo-Aristóteles secretum secretorum. Valencia: Universidad de Valencia, 2010.

Cañas Gálvez, Francisco de Paula. «La diplomacia castellana durante el reinado de Juan II: la participación de los letrados de la cancillería real en las embajadas regias». Anuario de Estudios Medievales, 2010, vol. 40, n. ${ }^{\circ}$, pp. 691-722.

Constance Mathers, Jones. «Students from Burgos at the Spanish College in Bologna (15001560)». The Sixteenth Century Journal. The Journal of Early Modern Studies, 1987, vol. 18, pp. 545-556.

Daumet, Georges. Étude sur l'alliance de la France et de la Castille au XIV et XV siècles. Paris: Émile Bouillon, 1898.

Daumet, Georges. Mémoire sur les relations de la France et la Castille de 1255 à 1320. Paris: Fontemoing, 1913.

DíAz IBÁŃEZ, Jorge. «La incorporación de la nobleza al alto clero en el reino de Castilla durante la Baja Edad Media». Anuario de Estudios Medievales, 2002, vol. 35, n. ${ }^{\circ} 3$, pp. 557-604.

DíAz Martín, Luis Vicente. «Los inicios de la política internacional de Castilla (1350-1410)». En RucquoI, Adeline (coord.). Realidad e imágenes del poder. España a fines de la Edad Media. Valladolid: Ámbito, 1988, pp. 57-84.

Galíndez de Carvajal, Lorenzo (comp.). Crónica del serenisimo príncipe don Juan II. En Crónicas de los Reyes de Castilla, Madrid: Rivadeneyra, 1876. 
LA FORMACIÓN DE LOS DIPLOMÁTICOS EN LA CASTILLA BAJOMEDIEVAL

ÓSCAR VILLARROEL GONZÁLEZ

García y García, Antonio. «Escolares ibéricos en Bolonia. 1300-1330». En Estudios sobre los orígenes de las universidades españolas. Homenaje de la Universidad de Valladolid a la Universidad de Bolonia en su IX centenario. Valladolid: Universidad de Valladolid, 1988, pp. 113-134.

GiLli, Patrick. «Ambassades et ambassadeurs dans la législation statutaire italienne (XIII ${ }^{\mathrm{e}} \mathrm{XIV}^{\mathrm{e}}$ siècle)». En Andretta, Stefano; Péquignot, Stéphane y Waquet, Jean Claude. De l'ambassadeur. Les écrits relatifs à l'ambassadeur et à l'art de négocier du Moyen Âge au debut du XIX siècle. Roma: École Française de Rome, 2015, pp. 57-85.

Gómez Redondo, Fernando. Historia de la prosa medieval castellana. Madrid: Cátedra, 19982007, 4 vols.

Las Siete Partidas, ed. Real Academia de la Historia. Madrid: Imprenta Real, 1807.

Llull, Ramón. Libro de las bestias, ed. Laureano Robles Carcedo. Madrid: Tecnos, 2006.

López de Ayala, Pedro. Crónica del rey don Pedro primero, ed. Cayetano Rosell en Crónicas de los Reyes de Castilla, vol. I, Biblioteca de Autores Españoles vol. 67. Madrid: Atlas, 1953.

Moeglin, Jean-Marie (dir.) y PÉQuignot, Stéphane. Diplomatie et «relations internationales» au Moyen Âge (IX -XVe siècle). Paris: Presses Universitaires de France, 2017.

Montojo Montojo, Vicente. «Los fondos archivísticos como fuentes para el estudio de las cancillerías reales en las edades Media y Moderna». Miscelánea Medieval Murciana, 1999-2000, vol. XXIII-XXIV, pp. 75-97.

Moxó y Ortiz de Villajos, Salvador de. «La elevación de los 'letrados' en la sociedad estamental del siglo XIV». En XII Semana de Estudios Medievales. Pamplona: Institución Príncipe de Viana, 1974, pp. 181-215.

Moxó y Ortiz de Villajos, Salvador de. «La promoción política y social de los 'letrados' en la corte de Alfonso XI». Hispania, 1975, vol. 15, pp. 5-29.

Moxó y Ortiz de Villajos, Salvador de. «La sociedad política castellana en la época de Alfonso XI». Hispania, 1975, vol. 35, n. ${ }^{\circ}$ extra 6, pp. 187-326.

Ochoa Brun, Miguel Ángel. Historia de la diplomacia española. Madrid: Ministerio de Asuntos Exteriores, 2003, vol. 3.

PÉQuignot, Stéphane. «Les ambassadeurs dans les miroirs de princes en Occident au Moyen Âge». En Andretta, Stefano; Péquignot, Stéphane y Waquet, Jean Claude. De l'ambassadeur. Les écrits relatifs à l'ambassadeur et à l'art de négocier du Moyen Âge au debut du XIXe siècle. Roma: École Française de Rome, 2015, pp. 33-55.

Pérez Martín, Antonio. «Españoles doctorados en Bolonia en derecho civil o canónico (13691788)». En Rodríguez-San Pedro Bezares, Luis Enrique (dir.). Las universidades hispánicas de la monarquia de los Austrias al Centralismo liberal. Salamanca: Universidad de Salamanca, 2000, pp. 373-386.

Peset Reig, Mariano y Alonso Romero, María Paz. «Las facultades de leyes». En RodríguezSan Pedro Bezares, Luis Enrique (coord.). Historia de la Universidad de Salamanca. III-1. Saberes y confluencias. Salamanca: Universidad de Salamanca, 2005, pp. 21-73.

Poridat de Poridades, ed. Lloyd A. Kasten. Madrid: Silverio Aguirre, 1957.

Queller, Donald E. The Office of Ambassador in the Middle Ages. Princeton: Princeton University Press, 1967.

Redondo García, Emilio y otros. «La educación durante la Edad Media». En Redondo García, Emilio (coord.). Introducción a la historia de la educación. Barcelona: Ariel, 2001, pp. 251-380.

Riвot García, Luis Antonio (coord.). Historia de la Universidad de Valladolid. Valladolid: Universidad de Valladolid, 1989.

Rodríguez de Diego, José Luis. «La formación del Archivo de Simancas en el siglo Xvi. Función y orden internos». En López Vidriero, M. a Luisa y Cátedra, Pedro M. (dirs.). Coleccionismo 
y bibliotecas (siglos XV-XVIII). Salamanca: Universidad de Salamanca-Patrimonio Nacional, 1998, pp. 519-557.

Rymer, Thomas. Foedera, conventiones, literae et cuiuscunque generis inter reges Angliae et alios quosvis... III-2. Hagae Comitis: Apud Joannem Neaulme, 1740.

Serra Estellés, Javier. «El Cisma de Occidente y la Asamblea de Medina del Campo de 13801381 en el ms. lat. 11745 de la Biblioteca Nacional de Francia». Anthologica Annua, 2010, vol. 57, pp. 33-303.

Serrano y Pineda, Luciano. "Alfonso XI y el papa Clemente VI durante el cerco de Algeciras». Cuadernos de Trabajo de la Escuela Española de Arqueología e Historia en Roma, 1915, pp. 1-33.

SuÁrez Fernández, Luis. «Política internacional de Enrique II». Hispania, 1956, vol. 16, n. ${ }^{\circ} 62$, pp. 16-129.

SuÁrez Fernández, Luis. Castilla, el Cisma y la crisis conciliar (1378-1440). Madrid: Consejo Superior de Investigaciones Científicas, 1960.

Suárez Fernández, Luis. Historia del reinado de Juan I de Castilla. Madrid: Universidad Autónoma, 1977, vol. I.

Velázquez de Figueroa, Vicente y otros. Historia de la Universidad de Valladolid. Valladolid: Imprenta Castellana, 1918.

Villarroel González, Óscar. "Corte y diplomacia en la Castilla bajomedieval». Mélanges de la Casa de Velázquez. Nouvelle série, 2015, vol. 45, n. ${ }^{\circ}$ 2, pp. 105-124.

Villarroel González, Óscar. «Diplomacia y construcción monárquica: la participación eclesiástica castellana». En Vilar, Herminia y Branco, Maria João. The Medieval Monarchy and its legitimating strategies: the role of ecclesiastics, scholars and jurists $\left(12^{\text {th }}-15^{\text {th }}\right.$ centuries), (en prensa).

Villarroel GonZÁlez, Óscar. "Eclesiásticos en la diplomacia castellana en el siglo XV». Anuario de Estudios Medievales, 2010, vol. 40, n. ${ }^{\circ}$ 2, pp. 791-819.

Villarroel González, Óscar. «Eclesiásticos en la negociación de la paz en la Castilla bajomedieval». En Arranz Guzmán, Ana; Rábade Obradó, María del Pilar y Villarroel GonzÁlez, Óscar. Guerra y paz en la Edad Media. Madrid: Sílex Ediciones, 2013, pp. 309-341.

Villarroel González, Óscar. «Formación para el servicio del rey y la Iglesia en la Castilla bajomedieval». En SABAtÉ, Flocel (ed.). La formació de la personalitat a l'Edat Mitjana. Lleida: Pagès editors, 2016, pp. 149-167.

Villarroel González, Oscar. «Los poderes imbricados: papado y monarquía». En Pena González, Miguel Anxo y Rodríguez-San Pedro Bezares, Luis Enrique (coords.). La universidad de Salamanca y el Pontificado en la Edad Media. Salamanca: Publicaciones Universidad Pontificia de Salamanca, 2014, pp. 89-107. 